\title{
New Insights from Multibody Dynamic Analyses of a Turnout System under Impact Loads
}

\author{
Mehmet Hamarat ${ }^{1}$, Sakdirat Kaewunruen ${ }^{2, *\left(\mathbb{D} \text {, Mayorkinos Papaelias }{ }^{3} \text { and Mika Silvast }\right.}{ }^{4}$ \\ 1 Department of Civil Engineering, School of Engineering, The University of Birmingham, \\ Birmingham B152TT, UK; mzh670@bham.ac.uk \\ 2 Birmingham Centre for Railway Research and Education, School of Engineering, The University \\ of Birmingham, Birmingham B152TT, UK \\ 3 School of Metallurgy and Materials, The University of Birmingham, Birmingham B152TT, UK; \\ m.papaelias@bham.ac.uk \\ 4 Loram Finland Oy, Yliopistonkatu 58 D, 33100 Tampere, Finland; mika.a.silvast@loram.com \\ * Correspondence: s.kaewunruen@bham.ac.uk
}

Received: 5 September 2019; Accepted: 25 September 2019; Published: 30 September 2019

Featured Application: The new findings highlight for the first time the dynamic phenomena of turnout systems considering composite, concrete and timber sleepers and bearers. It also brings in-depth insights stemmed from multi-body simulations of dynamic train-turnout interaction into the influential aspects of dynamic responses, load redistributions, dynamic impact factors and wheel/rail contact forces. The novel insights in the article can be used (not limited to) as a reference for the design, inspection and maintenance of railway switches and crossings.

\begin{abstract}
A railway turnout is an essential infrastructure for managing railway traffic flexibility. In contrast, it imposes restrictions on train operations such as lower operational speeds through the turnout due to the complex movements of trains over the turnout. This results in the large-amplitude dynamic responses of the train-turnout interaction. Previous studies have focused on the train-turnout interactions entailing the wheel-rail contact forces and stresses. Very few of the studies considered the effects of the contact forces on the turnout structure and its components such as sleepers and bearers. Those previous studies neglected the dynamic forces and estimated the behavior of train-turnout interactions based on quasi-static calculations. In reality, turnouts are subjected to high impact forces, which can be higher than the permissible track forces. Consequently, a numerical model capable of determining impact forces was developed here, to evaluate the dynamic behaviors of a railway turnout and their effects on such turnout components as bearers, ballast, and so on. The model consists of a structured beam grillage laying on an elastic foundation with rigid wheelsets and a bogie. The model was verified by field measurements. The new insight stemmed from this study shows that neglecting the contribution of dynamic forces can result in the unsafe underestimation of train turnout behaviors.
\end{abstract}

Keywords: railway; turnout; switches and crossings; impact forces; contact forces; wheel-rail interaction; bearers; sleepers

\section{Introduction}

A common method of changing the direction of a railway vehicle or diverting rail traffics from one route to another includes the use of railway turnouts, or so called 'switches and crossings', as illustrated in Figure 1. The design of a railway turnout entails multidisciplinary engineering to overcome the burdens of the complex geometry of a turnout, which imposes restrictions such as lower operational 
speeds and high-quality maintenance to prevent derailments. The average cost of turnouts is estimated at 26,000 Euros per km by Banverket in Sweden [1]. The cost occupies $24 \%$ of maintenance and $23 \%$ of renewal budgets in the UK [2]. Furthermore, approximately 12,000 turnout related derailments have been reported in the EU, the annual cost of which is an estimated 200 million Euros [3]. Consequently, they are considered to be a top concern for smooth traffic management by infrastructure managers in Europe [4].

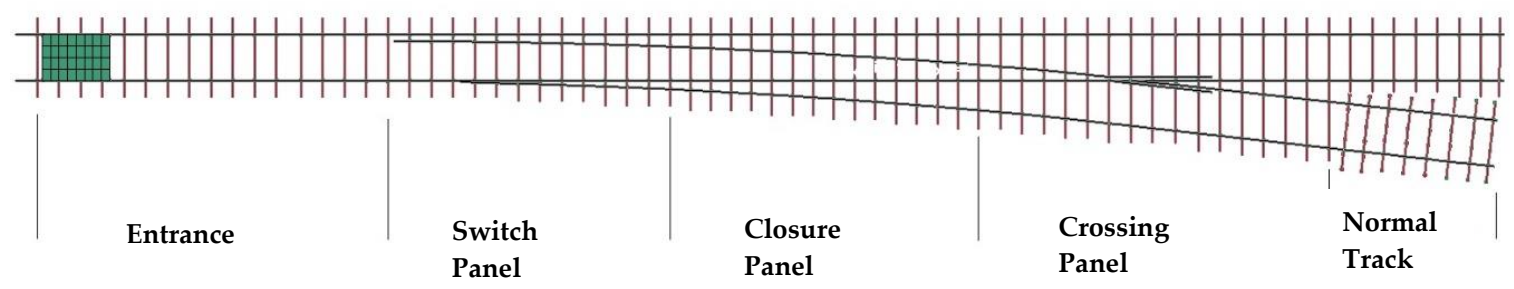

(a)

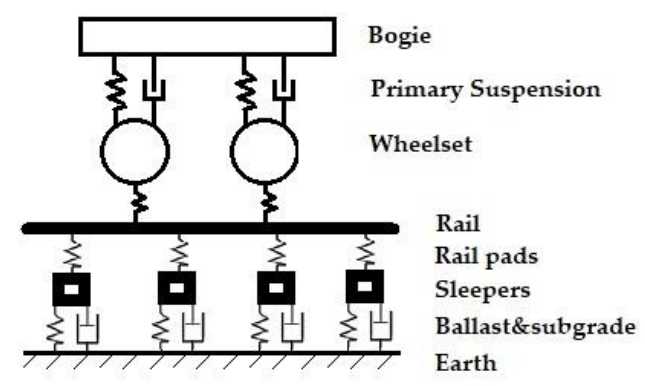

(b)

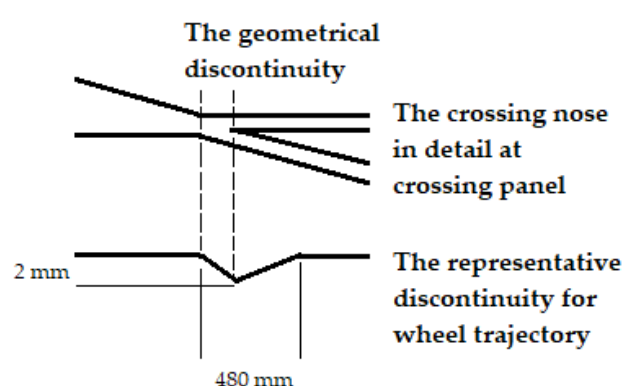

(c)

Figure 1. The Finite Element Method (FEM) model. (a) The layout of a standard turnout; (b) the schematic vehicle-track couple; and (c) the crossing nose and wheel trajectory.

Accordingly, many studies have been devoted to improving the design and performance of the railway turnout system. Several types of research have offered effective configurations (such as gauge widening [5] and movable crossings [6]) to mitigate dynamic wheel-rail forces and to improve ride comfort. In reality, fundamental problems, such as fatigue and plastic damage caused by impact forces and stiffness variations along a turnout, still attract the attention of many researchers [7-12]. Specifically, the number of studies has increased, in the last two decades, along with development of the computational power that facilitates the use of a numerical process. The reason behind opting for a numerical process is that analytical solutions are rare, and experimental setups to analyze the behavior of a turnout are expensive and time consuming. Furthermore, numerical tools provide a flexible environment for changing the parameters or generating various scenarios. The diverse applications of numerical methods include risk analysis [13], maintenance [14], failure detection [15], etc.; however, the general propensity here involves investigating the dynamic behavior of wheel-rail contact forces over a turnout globally or locally [5,9-12]. The main motivation was that the prediction of track force spectra can be used for service life predictions of the safety-critical components [16-20].

Global or whole turnout analyses were conducted to evaluate the general behavior of a turnout under static or dynamic conditions [9,11,12], to optimize the design of a turnout [5,21], or to tune the vertical track stiffness [22]. This type of analysis holds the advantage that the components of the track-vehicle couple are relatively simple/simply modeled and therefore, computationally less expensive. A common numerical tool for whole turnout analyses is multi-body simulation (MBS) 
where the bodies are simulated by multi degrees of freedom, and the contact theories are used to estimate contact forces. In general, Hertzian, Non-Hertzian, or Multi-Hertzian contact theories have been adopted to calculate normal contact forces and Kalker's theories or Polach's method have been used for tangential forces [23,24]. The disadvantage of the MBS is the limitation of the accuracy of estimated contact forces. For instance, it was found that the multi body simulation, having a resolution range over $500 \mathrm{~Hz}$, consumed a significant amount of time and resources [25] whereas rail irregularities range up to $2000 \mathrm{~Hz}$ [26]. As a consequence, particular studies [14,27-29] use quite detailed FEM (Finite Element Method) models to increase accuracy in the estimation of the contact forces. These FEM models require more computational power than MBS models, but their accuracy is higher and allows stress-strain level investigations on the contact patch. The disadvantage here is that the scale of modelling is reduced to overcome the computational cost. In other words, a specific location rather than a whole turnout is selected to investigate the dynamic behavior. There have been recent attempts to deal with computational costs $[27,30]$ which, while promising, are still insufficient to expand the simulation scale.

As discussed, most of the previous studies are focused on the wheel-rail interface. There also exists other research interest on turnout components such as sleepers and bearers [31,32]. Nevertheless, these models apply the simple moving load approach with a dynamic impact factor to simulate the worst-case scenarios of loading conditions over the turnout. This approach is incapable of capturing actual impact forces and may result in inaccurate results and interpretations. The current design codes for sleepers and bearers use similar quasi-static approaches. They rely on only static analysis with a dynamic factor to estimate the dynamic effects. In fact, the European standards did not have a design code until very recently they have introduced a design guideline resembling other design codes. Nonetheless, a recent study has questioned whether it is appropriate to use these design codes or similar methodology [33], since neglecting such impulsive forces may cause either under or over estimation of the dynamic behavior of components. As an example, the most critical part was incorrectly found between the crossing nose and switches [31], which contradicts actual field observations [7] and many of the other aforementioned studies. Impact forces, including both P1 (high frequency) and P2 (moderate frequency) forces, appear to be the decisive factor when assessing the reserve strength mechanism of a sleeper so as to achieve optimum sleeper lifecycle [26].

The aim of this study is to critically determine the dynamic behavior of a turnout system and to evaluate the effect of impact loadings on the bearers and sleepers by using an FEM-MBS coupled model that is capable of capturing the impact forces. According to a critical literature review, the dynamic behaviors of clustered turnout bearers and sleepers in a turnout system have not been fully investigated. The new insight stemmed from this study demonstrates the critical effects of dynamic loadings on the behavior of railway turnout bearers and sleepers. It could be used as a new reference indicator to develop a new design standard for railway sleepers and bearers. The paper demonstrates the development of a numerical model, followed by model verification, parametric studies, results, and finally conclusions. The effects of different speeds, axle loads, rail pads, and sleeper types are investigated, as well as the dynamic behavior of a turnout.

\section{Numerical Model}

\subsection{Geometry and Material Properties}

The FEM-MBS coupled model of a turnout was developed to investigate the dynamic behavior of a railway turnout subjected to dynamic impact loads. The track is modeled with FEM elements and the vehicle, and interactions between track and vehicle are defined by MBS elements. The coupling between the two models is provided by Hertzian Contact Theory. The model represents a right-hand turnout of 54E1/1:9 type consisting of an entrance, a switch, a closure panel and a crossing panel. The length is approximately $48 \mathrm{~m}$. A descriptive figure of the model is illustrated in Figure 1. Two common element types, beam elements for rails and sleepers, and linear springs—viscous dampers 
for substructure and rail pads-are used while modelling. The rails in the model have an equivalent rail profile compared to a standard UIC54 rail. The equivalent profile serves as an opportunity to reduce the model complexity as the stress-strain level investigation is not the main concern in the context. Furthermore, the rail surfaces are assumed to be perfectly smooth with the exception of a small irregularity representing the discontinuity found on the rail at the crossing panel in Figure 1c.

The connectivity between rails and sleepers is enabled by rail pads. In practice, the range of stiffness values for rail pads is rather wide, between 20 and $3032 \mathrm{kN} / \mathrm{mm}$ [6,34]. Selection of suitable rail pad is mainly based on experience and preference of the infrastructure managers. Hence, it is believed to be an effective and efficient approach to the select a rail pad stiffness regarding the similar values commonly used in the literature. In this model, a rail pad with a stiffness value of $1300 \mathrm{kN} / \mathrm{mm}$ is applied. Additionally, two stiffness values for different rail pads are collected and applied to simulate the conditions in the different reference cases $[5,10]$ for validation. It should be noted that the stiffness values are dynamic values obtained mostly by drop weight tests. An experimental study in [35] shows that maximum dynamic stiffness could be three times higher than static stiffness.

The model consists of 77 sleepers and bearers including both shorter sleepers and the longer bearers. The average spacing between sleepers/bearers is $0.71 \mathrm{~m}$. The sleepers/bearers have lengths varying from 2.44 to $4.7 \mathrm{~m}$ and supported by the ballast bed and subgrade. The ballast bed and subgrade is modeled by the use of a single-layered spring and damper couple representing the elastic foundation part of the 'beam on an elastic foundation concept' [6]. The collective stiffness and damping of this layer per normal sleeper is $45 \mathrm{kN} / \mathrm{mm}$ and $32 \mathrm{Ns} / \mathrm{mm}$ [27]. In addition, the stiffness and damping values per sleeper are adjusted along the turnout with reference to sleeper length.

The unsprung mass seems to be the most influential variable affecting the impact forces $[6,36]$. It is assumed in this study that the unsprung mass per wheel is 10 tons. The effect of the car body and inherently, the effect of consecutive bogies is neglected since they have limited effects. As a consequence, the vehicle is simplified as two rigid wheelsets and a rigid bogie. The wheelsets and the bogie are connected by linear springs and viscous dampers which represent primary suspensions. Stiffness and damping coefficients of the primary suspension are $1.15 \mathrm{MN} / \mathrm{m}$ and $2.5 \mathrm{kNs} / \mathrm{m}$ [27]. A summary of model properties could be found in Table 1.

Table 1. Dynamic material properties used in the numerical model.

\begin{tabular}{|c|c|c|c|c|}
\hline Element & Type & Number of Elements & Property & Value \\
\hline Rail & Beam & 1980 & $\begin{array}{c}\rho^{1} \\
\mathrm{E}^{2} \\
\mathrm{PR}^{3}\end{array}$ & $\begin{array}{c}7800 \\
210 \\
0.3\end{array}$ \\
\hline Sleeper & Beam & 3070 & $\begin{array}{c}\rho^{1} \\
\mathrm{E}^{2} \\
\mathrm{PR}^{3}\end{array}$ & $\begin{array}{c}2500 \\
38 \\
0.2\end{array}$ \\
\hline Rail Pad & Spring & 245 & $\mathrm{k}^{4}$ & 1300 \\
\hline Ballast & Spring/Damper & 5900 & $\begin{array}{l}\mathrm{k}^{4} \\
\mathrm{c}^{5}\end{array}$ & $\begin{array}{l}45 \\
32\end{array}$ \\
\hline Primary Suspension & Spring/Damper & 8 & $\begin{array}{l}\mathrm{k}^{4} \\
\mathrm{c}^{5}\end{array}$ & $\begin{array}{c}1.15 \\
2.5\end{array}$ \\
\hline
\end{tabular}

\subsection{Wheel-Rail Contact Model}

Several wheel-rail contact theories are used to estimate normal and tangential contact forces in numerical analysis procedures [23,24]. Hertzian Contact Theory for normal forces and Kalker's Fastsim for tangential forces are the most common and easy-to-adopt contact theories. However, they are mostly used during MBS modelling. In FEM, penalty-based contact models are mostly preferred. Selection of a contact model amongst these contact theories is related to the complexity of the numerical 
model. The model here is relatively simple, which is built with simple 2D beam elements. Furthermore, only the vertical contact forces are considered. More importantly, general behaviors such as sleeper behavior under dynamic loading are of interest rather than wheel-rail interface in this study. As a consequence, simple Hertzian contact theory is applied here to calculate contact forces. The formulation of the contact force is:

$$
F=k \cdot\left(\delta_{w}-\delta_{\mathrm{r}}-\delta_{i r}\right),
$$

where $k$ is the Hertzian spring constant and $\delta_{w}, \delta_{\mathrm{r}}, \delta_{i r}$ are the displacement values of the wheel, rail and track surface roughness at the location, respectively. The formulation of Hertzian contact stiffness is given in [6] for railway applications as:

$$
k=\sqrt[3]{\frac{3 E^{2} Q \sqrt[2]{R_{\text {wheel }} \cdot R_{\text {rail }}}}{2\left(1-v^{2}\right)^{2}}},
$$

where $E$ is modulus of elasticity, $v$ is Poisson's ratio, $Q$ is static wheel load, $R_{\text {wheel }}$ is wheel radius and $R_{\text {rail }}$ is rail profile radius. Based on this formulation, contact stiffness is calculated as $1.4 \times 10^{6} \mathrm{~N} / \mathrm{mm}$.

The track surface roughness, sometimes called as "irregularity", in the formula represents track irregularities (vertical rail levels), which affect the dynamic train-track interaction. In order to simulate realistic conditions, the track irregularities obtained by a track measurement car in [37] are used in this simulation. The vertical measurements of a $30 \mathrm{~km}$ track are divided into small sections, the length of which are the same as the $48 \mathrm{~m}$ turnout model. Afterwards, the sections are compared with respect to the mean values and standard deviations. The section with the highest standard deviation and mean value is selected for the worst case scenario. The selected irregularity is presented in Figure 2. The profile of track irregularities

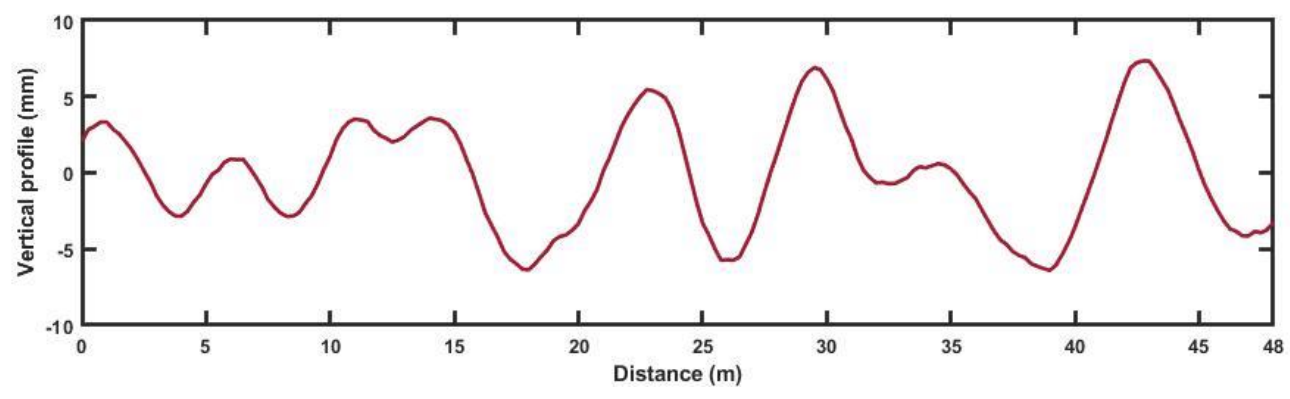

Figure 2. The profile of track irregularities (vertical rail levels).

\subsection{Analysis Procedure}

In simulation procedure, it is assumed that the vehicle travels at a constant speed in facing direction on the through route of the turnout. A $45 \mathrm{~m}$ travelling distance is used to calculate total simulation time which ensures that both wheelsets are on the track during simulation. It is also assumed that the components of track have degrees of freedom in their vertical planes and the spring-dampers representing the substructure are fixed in all directions. As a solver configuration, an explicit time integration with dynamic relaxation is selected [38]. In this procedure, the dynamic relaxation applies preloads which help the numerical model to approach an equilibrium where it starts to behave as if it is in a static condition. Otherwise, wheels subjected to gravitational forces would bounce on the rail and produce unrealistic vibrations. Dynamic relaxation is then followed by explicit time integration which uses the output of the preloading stage containing the information of nodal displacements and calculates nodal displacement in every time step until total simulation time is achieved. Explicit time integration is effective for simulating dynamic problems owing to its guaranteed convergence property. Nevertheless, its efficiency depends on the mesh size that affects the time step for the simulation. The smaller elements mean smaller time steps and therefore, the explicit time integration could be 
computationally extremely expensive for a poor meshing strategy. Importantly, in turnout simulations, the mesh size should be small enough to capture impact forces $\left(\sim 10^{-4} \mathrm{~s}\right)$ but also larger to shorten the simulation time. The time step in this simulation is adjusted as $\left(\sim 10^{-6} \mathrm{~s}\right)$ via trial and error to obtain a fine resolution while plotting the bending moment graphs.

\section{Verification of the Model}

A number of field measurements can be found in the open literature, the aim of which were to identify the dynamic behavior of a railway turnout [10,39-41]. It should be noted that most of them were conducted to verify numerical models. These measurements can be categorized into two groups: a measurement of accelerations [10,40] and a measurement of contact forces [39,41]. Validations by acceleration are commonly used as a direct method where the outputs produced by accelerometers were used. Nevertheless, it is difficult to determine contact force information directly from acceleration measurements. Therefore, validations by the measurement of contact forces are also preferred, where the contact forces were estimated by the output obtained from strain gauges.

The numerical model used in this study has thus been verified by using the existing literature, which can be considered to be reasonable and feasible. The two methods in the previous paragraph are considered for validation purposes, to ensure the accuracy of the numerical model. To consider the two different cases, the input parameters such as speed, axle load, and stiffness values are adjusted to be similar to those of the reference cases $[10,39]$.

The model in this study was compared with the field measurement in [10]. On one hand, the maximum acceleration is found to be $201.6 \mathrm{~m} / \mathrm{s}^{2}$, as shown in Figure $3 \mathrm{a}$, which is consistent with the result in [10] where the maximum positive acceleration reaches $214.05 \mathrm{~m} / \mathrm{s}^{2}$. The discrepancy between two cases is around 6\%. On the other hand, contact forces along a turnout can be presented in Figure $3 \mathrm{~b}$. It is noted that the maximum contact force occurs at the crossing panel and the magnitude can be up to $180 \mathrm{kN}$. These results are consistent with the field measurements in [39] where the impact forces can be measured between 150 and $200 \mathrm{kN}$. Here, it should be noted that exact conditions for field measurements in $[10,39]$ are unknown. Furthermore, the output of numerical simulations is deterministic whereas an element of uncertainty exists in the field measurements. Hence, discrepancies inherently and inevitably occur between the field measurements and the results of the simulation. Consequently, it can be concluded that the model carries similar attributes to the field measurement, and has sufficient accuracy, to represent the main dynamic characteristics of train-track interaction over a turnout.

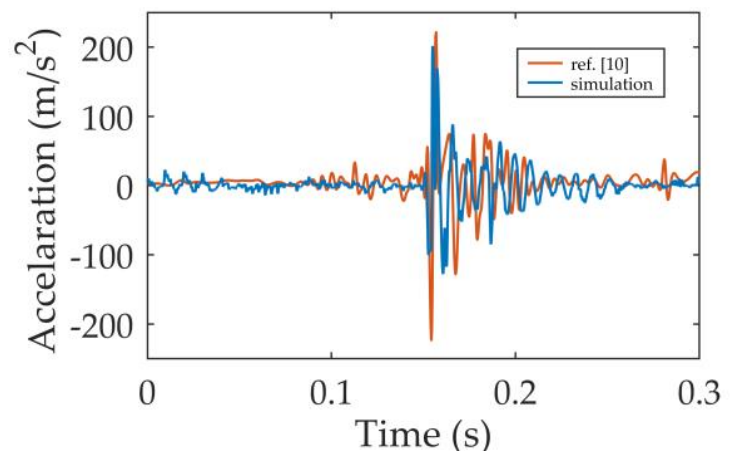

(a)

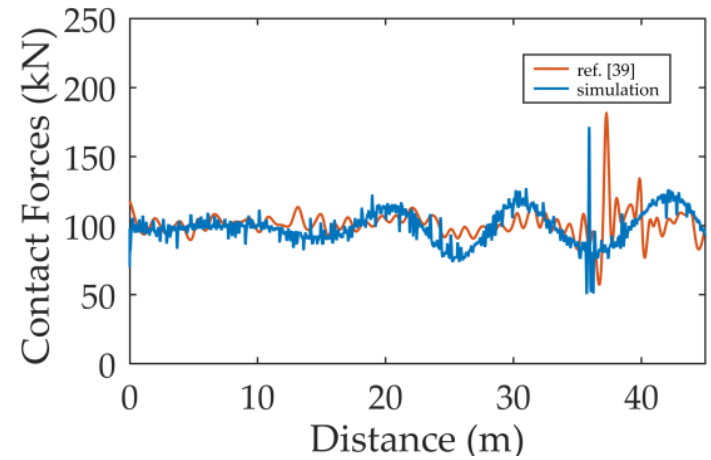

(b)

Figure 3. Multibody simulation and field data: (a) Vertical acceleration of the front wheel for comparison [10]; (b) normal contact forces along a turnout for comparison [39]. 


\section{Results and Discussion}

The result of the numerical simulation for the dynamic behavior of a railway turnout is presented in this section. It should be noted that the longitudinal bending moment distributions are plotted when the maximum positive or negative bending moment is observed. Conversely, bending moment distributions along sleepers and bearers are displayed only for the time step when the maximum positive bending moment occurs for the specific sleepers. As such, discrepancies between the maximum negative bending moments in the longitudinal bending moment distribution and in bending distribution along a sleeper can be observed for specific sleepers.

\subsection{Bending Moment Distributions under Static and Dynamic Loadings}

In Figure 4, the maximum positive bending moment distributions of five sleepers are illustrated under both static and dynamic conditions, where the vehicle speed is $50 \mathrm{~m} / \mathrm{s}$. It is observed in current model that the speed values over $50 \mathrm{~m} / \mathrm{s}$ result in so called wheel-fly, which indicates the absence of contact between wheel and rail. Here, the static condition means that an equivalent static wheel load is applied to the rail at specific locations. These are selected from the various locations of sleepers: at the entrance panel, a sleeper under the switch blade, the middle sleeper in the closure panel, a sleeper under the crossing nose, the longest sleeper and shortest sleeper. As can be seen from the Figure 4, the bending moment distribution is related to the sleeper length and the rail layout over the sleepers. Sleepers in the entrance panel, under the switch blades and the shortest sleeper show almost symmetrical distributions for both cases. Each sleeper shows small variations in bending moment distributions which are unique to their layout. For instance, the free switch blade creates a small indentation over the bending moment distribution of the sleeper under the switch blade (see Figure $4 \mathrm{~b}$ ). Likewise, there is a small difference in the distribution of the positive bending moments along the shortest sleeper, where the magnitude of the bending moment at the inside rail seat is lower than at the other side (see Figure 4f). It may result from the asymmetrical rail positioning which is carried out to place shorter sleepers or a sudden change in sleeper lengths from the longest to the shortest, which affects the bending moment distributions in the longitudinal direction. In general, the bending moment distributions of these sleepers, under dynamic loading, exhibit similar behavior to static loading. The small variations between static and dynamic cases are the consequence of track irregularities. The irregularities act as an actuator that produces force fluctuations ('dynamics') over the turnout. In the absence of irregularities, the force induced by train will be constant moving load and therefore, discrepancies cannot be observed between static and dynamic cases. For the dynamic case, the bending moment values are higher than the static values for these sleepers. Nevertheless, the difference is imperceptible and on some occasions such as in Figure $4 \mathrm{f}$, dynamic bending moments at one rail seat could have similar values to the static values. Another common point for these sleepers is that the maximum positive bending moments for these sleepers occur at the rail seats and the negative bending moments at the midpoint or close to midpoint of the sleeper. The magnitudes of maximum positive and negative bending moments are respectively around 5 and $4 \mathrm{kNm}$.

Figure $4 \mathrm{c}-\mathrm{e}$ show that the asymmetrical distributions of bending moments are observed for the sleepers at the closure and crossing panels and at the longest sleeper due to the expanding sleeper lengths and rail layout. It seems that the layout of a turnout affects the track stiffness significantly and results in the different distributions of the bending moments; specifically, it is obvious for the static case. The magnitude of the maximum positive bending moment, under static conditions, is the highest, $11.2 \mathrm{kNm}$, for the sleeper at the middle of the closure panel and next is the longest sleeper at $9.5 \mathrm{kNm}$. The maximum positive bending moments still occur at the sleeper sections under the rail seats and they are approximately twice as high as the positive bending moments at the opposite rail seats. A similar asymmetrical behavior is observed for the maximum negative bending moments and there are also similar differences between the sleepers in closure and crossing panels in terms of maximum negative bending moment. Nevertheless, the gap, between the magnitudes of maximum negative bending moments for these sleepers, is small at about $0.5 \mathrm{kNm}$. Unlike the maximum positive 
bending moments, the maximum negative bending moments occur at different locations along the sleeper. The location of the maximum negative bending moment of the sleeper at the closure panel is between two loaded rails; indeed, at the idle rail seat between two rails. In contrast, the longest sleeper possesses a maximum negative bending moment at the rail seat on the diverging route which is close to the route. Common points among the results for these two sleepers are their dynamic and static simulations. It seems that both are affected by track irregularities but the sleeper at the closure panel is more sensitive to track irregularities. The gap between static and dynamic is $2.7 \mathrm{kNm}$ for the sleeper at the closure panel whereas $1.5 \mathrm{kNm}$ for the longest sleeper. Interestingly, a small difference between the two sleepers is perceptible in that the sleeper sections under the straight rail seem to be affected differently despite having the same levels of irregularities applied at the same location. It is likely that the idle rails increase load distribution capacity and therefore, the ratio of gain changes with reference to distance between idle and loaded rails.

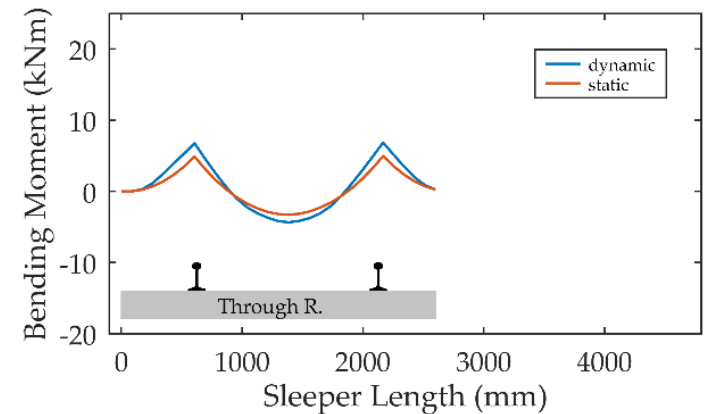

(a)

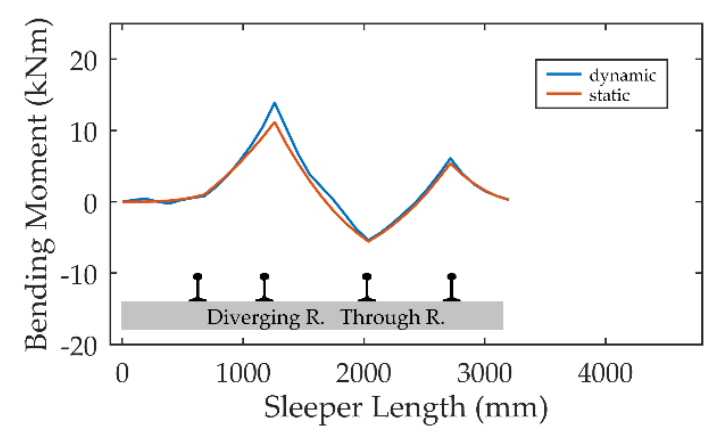

(c)

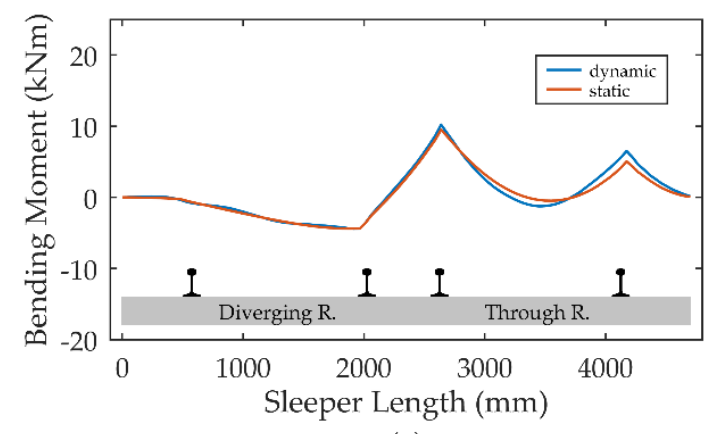

(e)

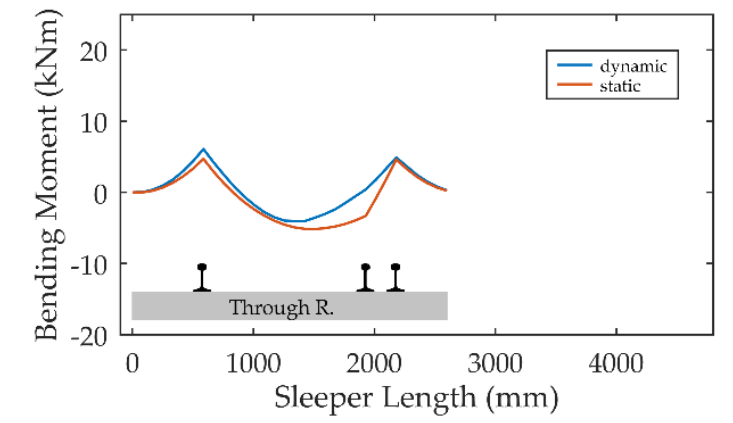

(b)

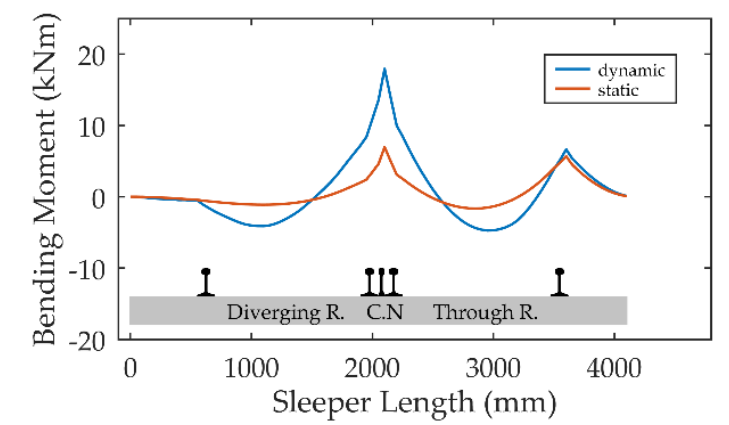

(d)

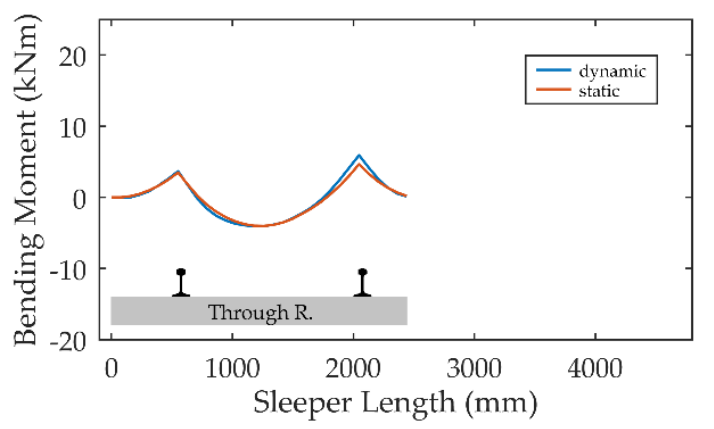

(f)

Figure 4. Flexural responses of sleepers and bearers: (a) Sleeper at the entrance; (b) sleeper under the switch blades; (c) sleeper at the closure panel; (d) sleeper under the crossing nose; (e) the longest sleeper; (f) the shortest sleeper.

Among the graphs in Figure 4, the most distinguishable is that of the bending moment distribution for the sleeper/bearer under the crossing nose. The static behavior of this sleeper is somehow similar to the sleeper at the entrance since the bending moments under rails seats are at the similar level of $6 \mathrm{kNm}$ 
with a kind of symmetry. Similarly, the maximum negative bending moment occurs at the mid-points of the loaded rails. On the other hand, the effect of the dynamic load on the maximum positive bending moment of the sleeper is evident in comparison with the other sleepers. The maximum positive bending moment develops at the sleeper section under the crossing nose at a level of $18 \mathrm{kNm}$. It is 2.7 times greater than the maximum positive bending moment for the opposite rail seat. Furthermore, the ratio of the maximum positive bending moment of dynamic loading when compared to static loading is 2.6. Whereas, the ratio reaches at 1.25 for the sleeper at the closure panel in comparison with the other sleepers. Finally, a similar conclusion is also valid for the maximum negative bending moments under dynamic loading. They significantly increase to $-4.7 \mathrm{kNm}$ and occur at similar locations as the static loading.

\subsection{Parametric Studies}

\subsubsection{Effects of Train Speed}

Dynamic excitations along a railway track are a function of the vehicle velocity. In this study, an investigation into the effects of train speed on a turnout and sleepers was also conducted. The train speeds used ranged from 10 to $55 \mathrm{~m} / \mathrm{s}$, which respectively approximately correspond to the minimum $(32 \mathrm{~km} / \mathrm{h})$ and the maximum $(200 \mathrm{~km} / \mathrm{h})$ permissible speeds through switches and crossings in the UK [42]. It is noted that a movable crossing nose is commonly used at speeds over $55 \mathrm{~m} / \mathrm{s}$ [6].

The relation between dynamic factor together with contact forces against speed is presented in for two cases: where the track is perfectly smooth, and a track with irregularities. The definition of the dynamic factor is the maximum dynamic force over the static load and; therefore, both the impact-induced, so called P1 and P2 forces, and dynamic wheel forces are considered. P1 is defined as the high frequency impact force due to irregularities with small wavelengths and is mostly higher than the P2 forces. Moderate frequency impact force (P2) is defined as an impact force following P1 forces and cannot exceed the threshold of $322 \mathrm{kN}$ according to Rail Safety and Standards Board (RSSB) [43]. Indeed, several definitions of P2 forces exist in the literature. The definition used here is selected for clarity. By contrast, dynamic forces are defined as track forces in the range between static and impact forces. It is expected that impact forces are higher than dynamic forces on an ideal track where dynamic forces are equal to static forces. Nevertheless, dynamic forces could be higher than static values or even P1 forces, on the track with irregularities, based on the severity of the irregularity and the vehicle speed. This possibility is noticeable in Figure 5a. In ideal cases, the dynamic factor is purely due to impact forces. Conversely, dynamic forces prevail at lower speeds (up to $30 \mathrm{~m} / \mathrm{s}$ ) with irregularities present; therefore, the dynamic factor fluctuates around the ideal case below $30 \mathrm{~m} / \mathrm{s}$. Furthermore, the maximum forces could exist anywhere along the turnout at speeds below $30 \mathrm{~m} / \mathrm{s}$. Contrarily, the dynamic behaviors under both track conditions show similar properties over the speed of $30 \mathrm{~m} / \mathrm{s}$. The case with irregularities has a slightly higher dynamic factor than the ideal case. This is due to the selected track irregularities and the contact force formulation. Here, track irregularities have extra contributions to contact forces, which may be accepted as degradation. As can be seen from the figure, the non-linear correlation between dynamic factor and velocity shows that higher velocities cause higher impact forces for both cases and dynamic factors could reach up to 3.2. It is worth mentioning that the instant wheel load or impact force, here approximately $318 \mathrm{kN}$, is close to the limit of the permissible wheel force which is defined as $322 \mathrm{kN}$ by RSSB [43]. However, the P1 portion of the impact induced wheel forces could be higher $[36,44,45]$ than this threshold, but they are mostly acceptable as the duration of the impact is small. 


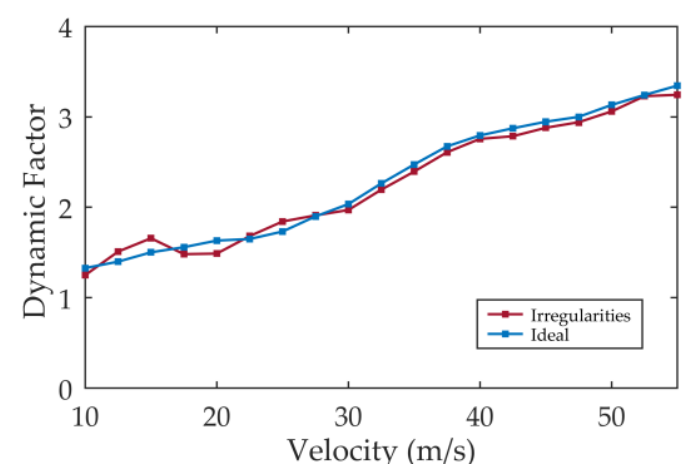

(a)

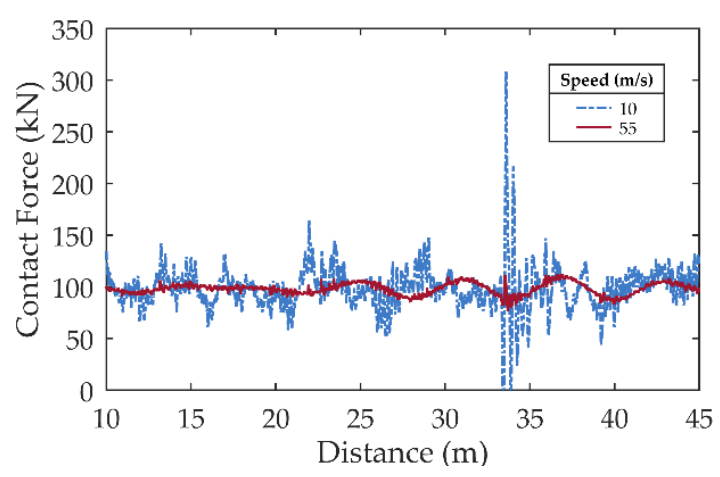

(b)

Figure 5. Multibody responses: (a) Dynamic factors for two cases: track with no irregularities and with irregularities; (b) contact forces for minimum and maximum speed.

As aforementioned, both numerical studies and field measurements $[7,11,32,40]$ show that the highest contact forces and vertical accelerations of the wheelsets are observed at the crossing panel, particularly at the crossing nose. The common insight in these studies is that the most critical part of a turnout is the crossing panel. Nevertheless, such a conclusion seems inaccurate; in [31] where it is shown that sleepers at closure panels are subjected to the highest bending moments under moving constant loads. Interestingly, the findings in the previous section confirm both results, which show that the critical section could be either at closure panel or crossing panel based on vehicle speed. To understand the origin of the discrepancy between studies, it is crucial to investigate the longitudinal bending moment distributions of turnout components for different vehicle speeds.

In Figure 6, the longitudinal bending moment distribution is displayed for a case when the vehicle runs over a track without irregularities. The bending moment distribution shows that maximum bending moments at lower speeds gradually increase with the sleeper length, with the exception of a small drop at the sleepers under the crossing nose. The relatively lower bending moments at the crossing panel could be a consequence of the increased total rail stiffness, which evenly distributes the load between sleepers. The distinct property of Figure 6 is that significant variations could be observed only at the crossing panel with no track irregularities. As can be seen from Figure 6, maximum positive bending moments as well as maximum negative bending moments mostly take place at sleepers close to the crossing nose and the deviation between the bending moments at minimum and maximum speeds is large. Another insight stemmed from Figure 6 is that the open switch blade increases the maximum negative bending moment; therefore, the maximum negative bending moment starts to increase a few sleepers before.

In Figure 7, maximum positive and negative bending moments are presented for different vehicle speeds travelling on a track with irregularities. It is evident that the location of the maximum bending moment is related to vehicle speed. At lower speeds, maximum positive bending moments appear to occur at closure panels and the magnitudes of the positive bending moments are 10-15 kNm with reference to vehicle speed. Likewise, maximum negative bending moments take place in the vicinity of the location of the maximum positive bending moments, with magnitudes of around $7 \mathrm{kNm}$. For both moment directions Figure 7, there are fluctuations in the bending moments, which are as a result of track irregularities. 


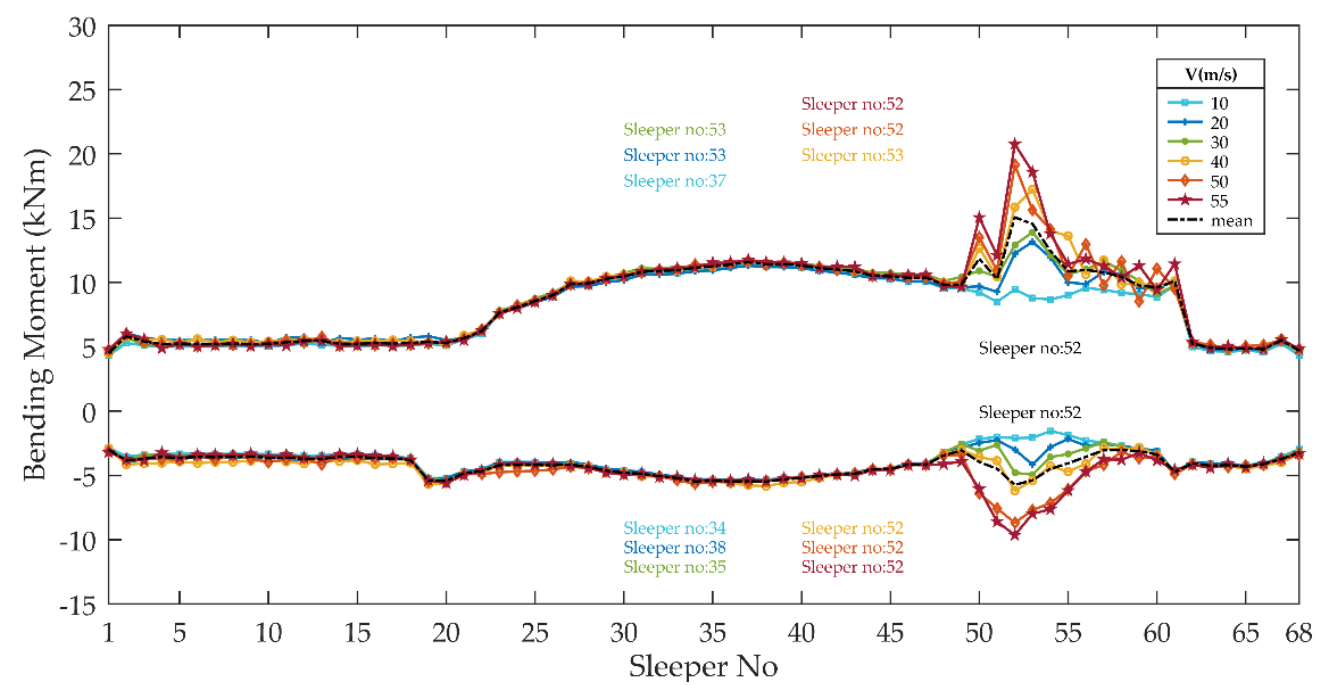

Figure 6. Longitudinal bending moment distribution with no track irregularities.

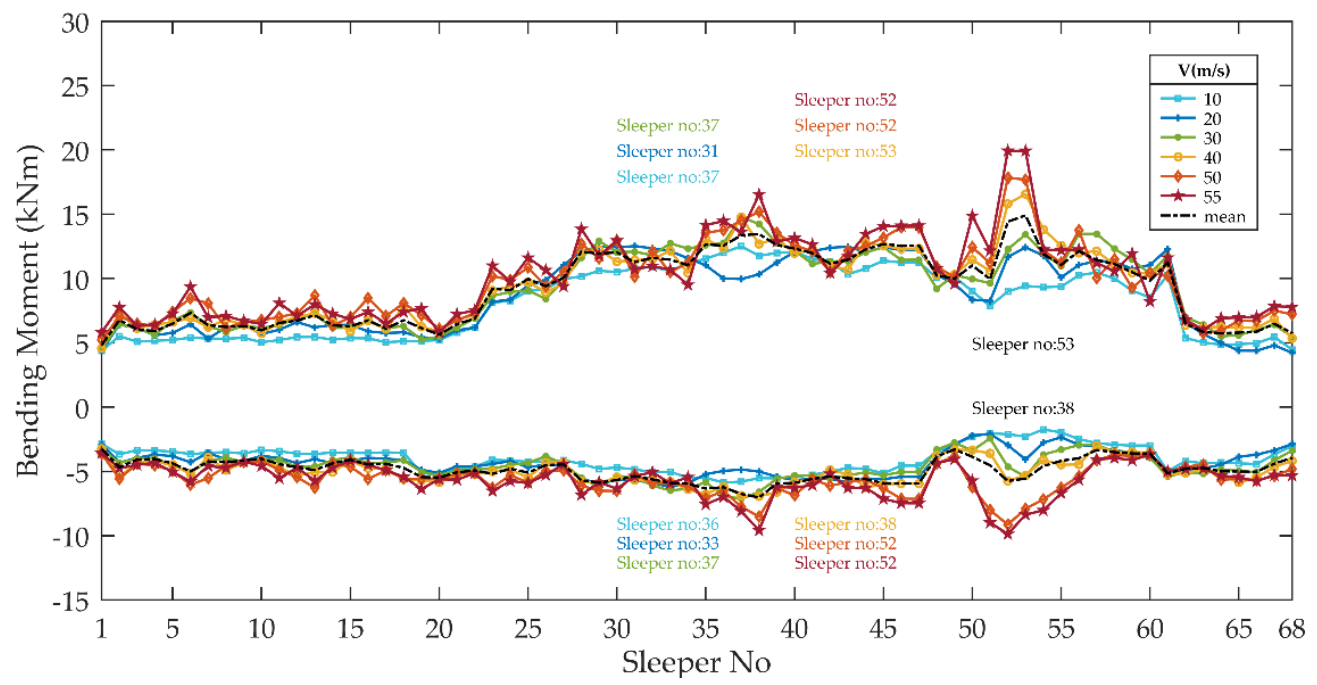

Figure 7. Longitudinal bending moment distribution with track irregularities.

Interestingly, higher train speeds produce a significant difference in the maximum positive bending moment distributions along the turnout. The location of the maximum positive and negative bending moments shifts from the closure panels to the crossing panels with higher speeds. The reason for this shift is that the effects of impact forces become more distinct, parallel to speed increments. The magnitude of the maximum bending moment is $20 \mathrm{kNm}$ at the speed of $55 \mathrm{~m} / \mathrm{s}$., which is approximately four times higher than normal for that track section. Interestingly, track irregularities still produce higher bending moments and therefore, the maximum positive bending moments at closure panels are still significant. Nevertheless, these become insignificant when compared with the gain at the crossing panel. Similarly, the negative bending moments also distinctly seem to have shifted their location from the sleepers at the closure panel to the sleepers under the crossing nose. However, the maximum negative bending moments show smaller increases compared to the maximum positive bending moments.

The contribution of the track irregularities to bending moments is clear by the comparison of Figures 6 and 7. Irregularities have a limited effect on the bending moments of the sleepers under the crossing nose, in contrast to other sleepers. For instance, the gap between maximum bending moments in two cases for sleeper 52 is $1 \mathrm{kNm}$; by contrast, it is $5 \mathrm{kNm}$ for the sleeper 38 . Another significant aspect of this comparison is that the standard deviation of the bending moments due to 
track irregularities could be significant which is important in terms of fatigue damage. The fatigue damage occurs under cyclic loadings; the mean force and force amplitudes define the stress cycle [46]. In addition, this comparison gives another proof for the effects of track irregularities. The location of the mean value of the maximum negative bending moment shifts from the sleeper under the crossing nose to sleeper at the closure panel. Consequently, neglecting track irregularities could lead to miscalculations.

The longitudinal distributions of the maximum positive and negative bending moments are significantly influenced by speed variations; therefore, the bending moment distributions of specific sleepers under various speed are portrayed in Figure 8. The common point of each graph is that the maximum positive bending moments occur at rail seats for all speed variations. Conversely, maximum negative bending moments are observed at different locations. For instance, the location of the maximum negative bending moment for some sleepers, such as the sleepers at the entrance, under the closed switch blades, under the crossing nose and the shortest sleeper, is the sleeper section in the vicinity of the midpoint of track. This is in contrast to the other locations, particularly at the rail seats close to the loaded rail seats, for the sleepers at the closure panel, and the longest sleeper. Figure 8 also demonstrates that the effects of various speeds on the maximum positive bending moment distributions seem to be diverse for each sleeper. As an example, maximum velocities cause higher bending moments at sleeper sections under one rail or both rails for several sleepers, but occasionally lower bending moments for specific sleepers. This is due to the time step when the maximum positive bending moment occurs. At this time step, the location of the wheels could be different for each case; therefore, the longitudinal bending moment distribution, which is affected by speed and irregularities, shows variations that also affect the bending moment distribution along a sleeper. As a result, it is a challenge to make a reliable comment on the effects of irregularities on the bending moment distributions along a sleeper. On the contrary, it is obvious that higher speeds cause higher positive and maximum bending moments at the sleeper section under the crossing nose owing to the discontinuity at this section. The gap between minimum speed and maximum speed, in terms of the maximum positive bending moment at the section under the crossing nose, is about $11 \mathrm{kNm}$. Likewise, it is $8 \mathrm{kNm}$ for maximum negative bending moment.

\subsubsection{Effects of Rail Pads}

Rail pads are used between rails and sleepers/bearers to increase the elasticity of the track. This affects the dynamic response of the track, such as vibration characteristics and stress distributions [6]. The dynamic response is a decisive factor with regards to safety, the lifecycle of components and passenger comfort. Based on the common assumption that track stiffness is the combination of rail pad, superstructure, and substructure stiffness [6,47], a parametric study of varied rail pad stiffness is considered, using a vehicle speed of $50 \mathrm{~m} / \mathrm{s}$. In reality, rail pads have damping properties, but the effects of rail pad damping on impact responses have been found to be minimal in comparison to overall track damping of well compacted ballast bed [48]. Moreover, damping is a complex phenomenon and expected to be less effective under impact force that cannot be damped out in such a very short duration. As a consequence, rail pad stiffness is considered.

Figures 9 and 10 show the influence of the rail pads on the longitudinal bending moment distributions together with contact forces. It is clear that the increase of rail pad stiffness causes higher positive and negative bending moments along the turnout. The maximum positive bending moment occurs at the sleepers under the crossing nose under all conditions. Nevertheless, the maximum negative bending moments could be observed at different locations. The reason seems to be the vibration response of the vehicle. For instance, the lowest rail pad stiffness produce higher contact forces while the train moves from the longest sleeper to shortest sleeper (see Figure 9b). 


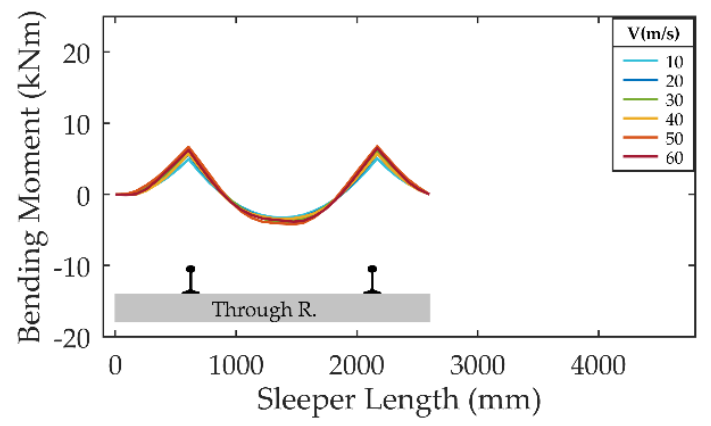

(a)

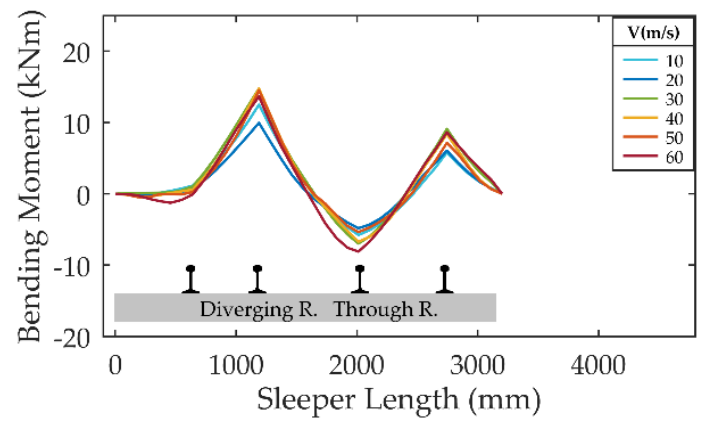

(c)

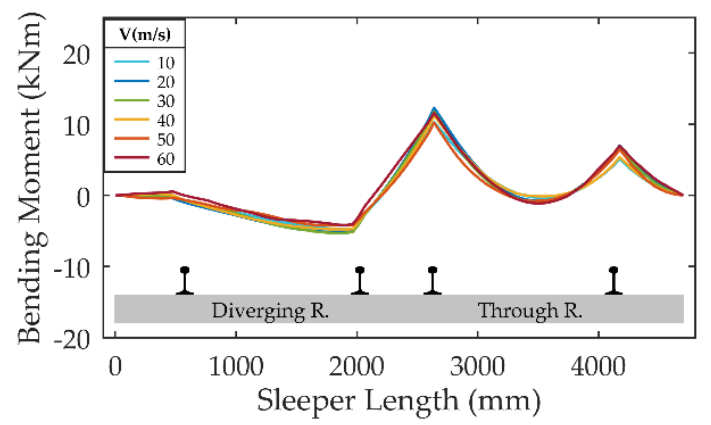

(e)

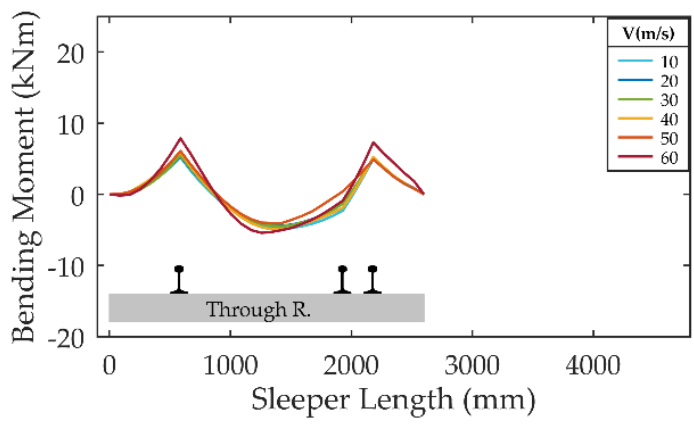

(b)

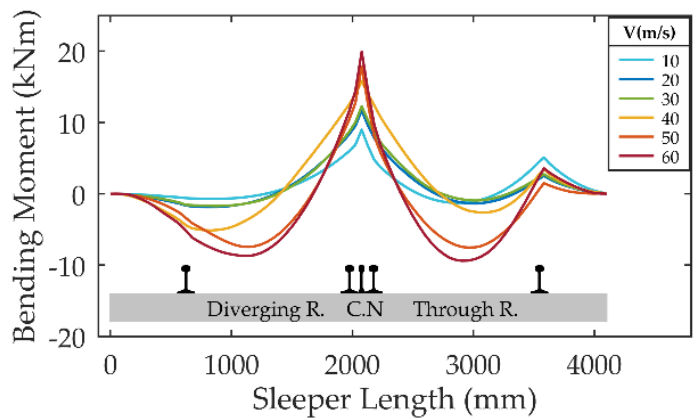

(d)

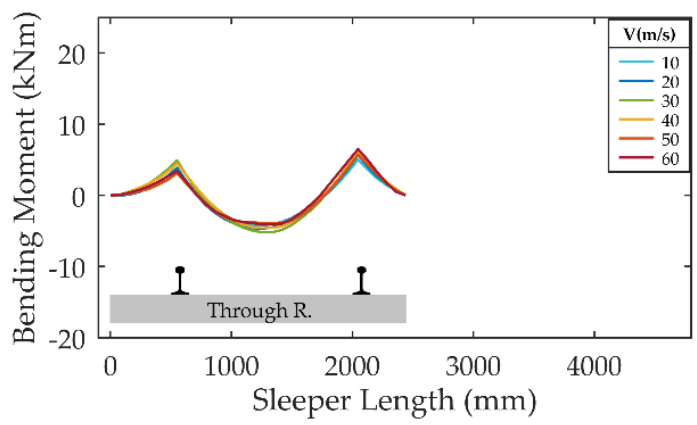

(f)

Figure 8. Flexural responses of sleepers and bearers: (a) Sleeper at the entrance; (b) sleeper under the switch blade; (c) sleeper at the closure panel; (d) sleeper under the crossing nose; (e) the longest sleeper; (f) the shortest sleeper.

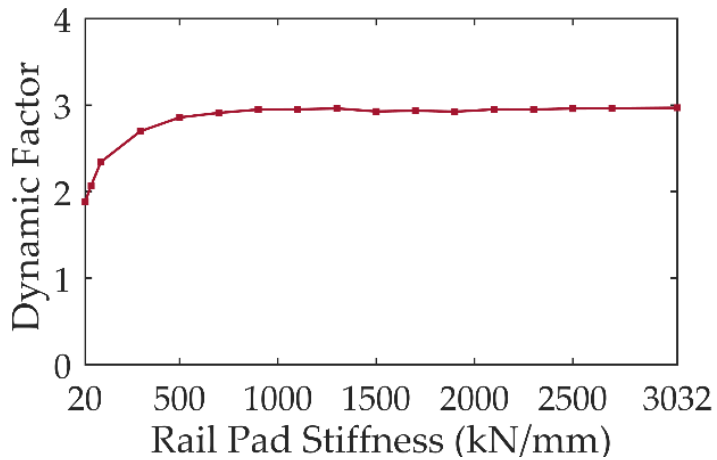

(a)

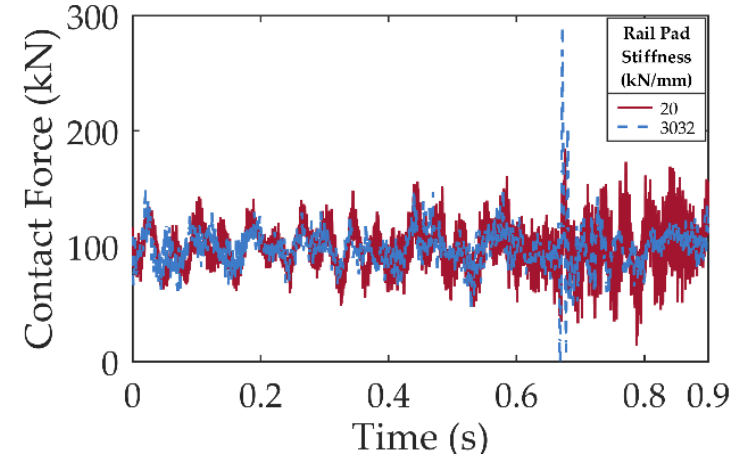

(b)

Figure 9. Dynamic effects: (a) Variations in dynamic factor which correspond to rail pad stiffness; (b) contact forces for minimum and maximum rail pad stiffness. 


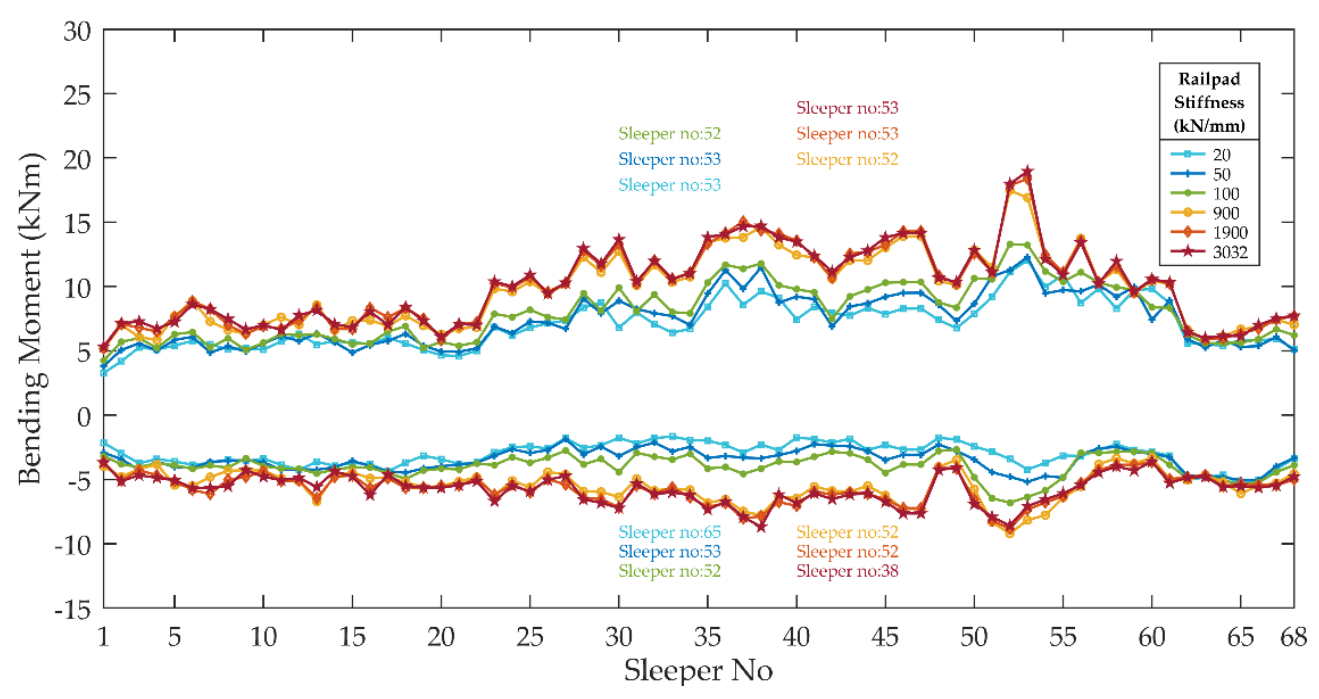

Figure 10. Longitudinal bending moment distributions with reference to different rail pad stiffness.

The magnitudes of the maximum positive and negative bending moments, for the maximum rail pad stiffness, differ significantly from the minimum rail pad stiffness for most of the sleepers. The maximum gap between maximum positive bending moments for maximum and minimum rail pad stiffness is $10 \mathrm{kNm}$ at the crossing section and similarly, it $5 \mathrm{kNm}$ between maximum negative bending moments. Interestingly, the maximum gap becomes small at the sleepers after the crossing nose. The reason is that lower stiffness excites higher forces, on those sleepers, which closes the maximum gap between maximum positive bending moments as well as maximum negative bending moments for maximum and minimum rail pad stiffness. As can be seen from Figure 9a, the rail pad stiffness influences the dynamic factor to some extent such that the effect of the rail pad appears to be insignificant. Furthermore, contact forces on the wheel-rail interface before the crossing nose appear to be less sensitive to variations in rail pad stiffness Figure 9b. Consequently, it may be concluded that softer rail pads are efficient for the lifecycle of sleepers before the crossing nose.

The bending moment distributions of specific sleepers, with different rail pad stiffnesses, are presented in Figure 11. The bending moment distributions mostly follow similar behaviors to those seen in previous sections, such as the location of maximum positive and negative bending moments at the particular time step. It seems that the longer sleepers are influenced more by rail pad stiffness variations. More interestingly, maximum negative moments show larger deviations. For instance, the maximum positive bending moment on the sleeper under the crossing nose ranges from 12 to $18 \mathrm{kNm}$. By contrast, the location of maximum negative moments for same sleeper changes and ranges from 1 to $9 \mathrm{kNm}$. Additionally, there is no negative bending moment between loaded rails when the rail pad stiffness is $20 \mathrm{kN} / \mathrm{mm}$.

\subsubsection{Effects of Sleeper Stiffness}

In general, the permissible contact pressure on the ballast bed is theoretically below a range between 0.5 and $0.75 \mathrm{MPa}$ depending on the geological type of ballast [6]. To satisfy this condition, sleepers undertake the vital role of distributing the wheel loads across the underlying ballast bed [26]. Most of the numerical track models basically rely on the theory of a beam on an elastic foundation where the rail is supported by an elastic support. For the cases where the sleeper is of interest, the theory is developed into that of a sleeper resting on an elastic foundation [6]. According to the theory, the effectiveness of the stress distribution from sleeper to ballast bed correlates with the flexibility of the sleeper, which is the function of the modulus of elasticity of the sleeper; the modulus of elasticity is a material property. The most common sleeper material is concrete; thus, a parametric study considering the changes in the moduli of elasticity of a concrete sleeper is conducted. 


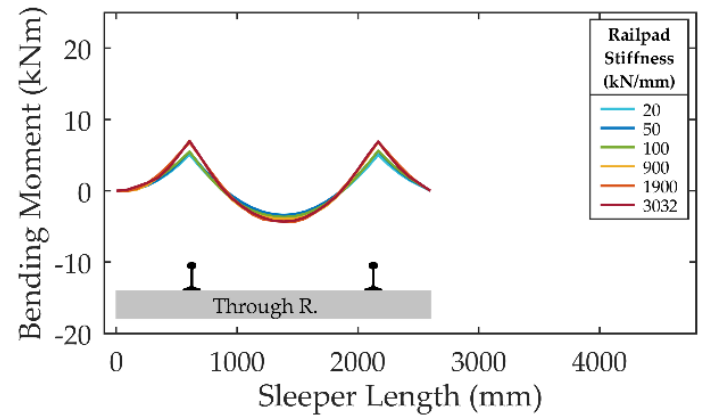

(a)

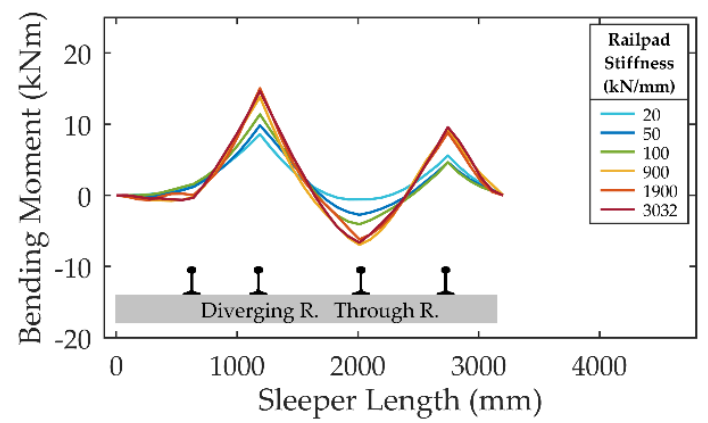

(c)

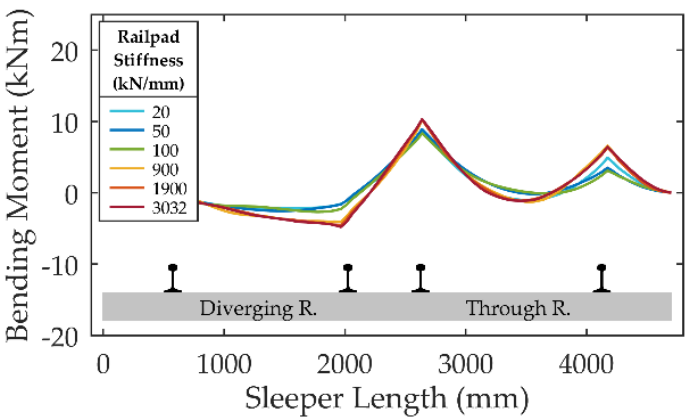

(e)

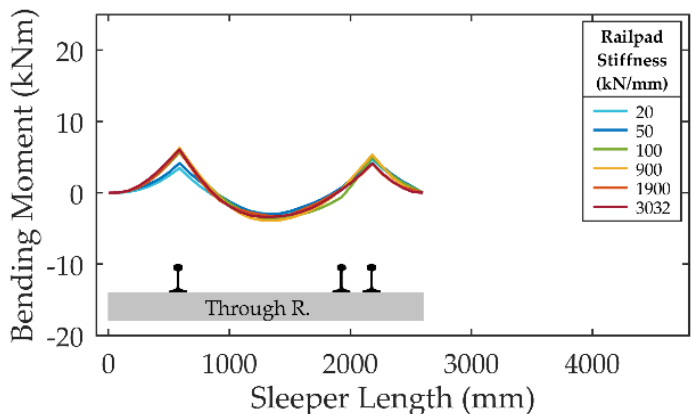

(b)

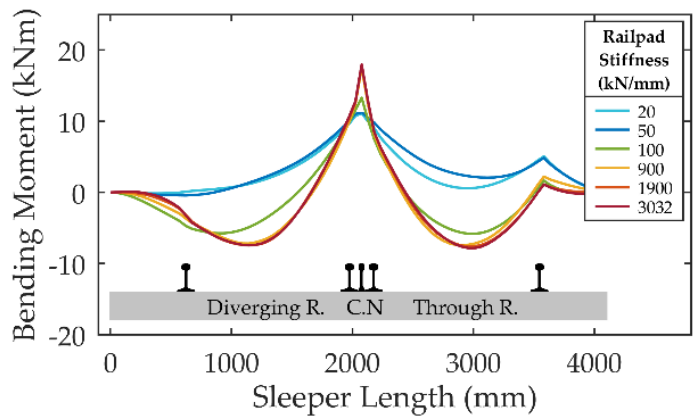

(d)

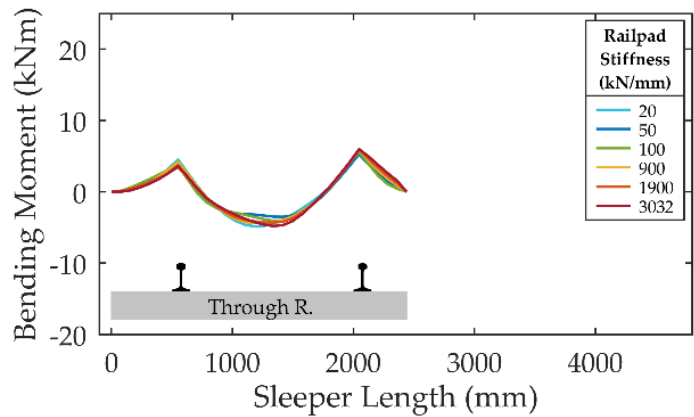

(f)

Figure 11. Bending moment distributions of specific sleepers with reference to different rail pad stiffness: (a) sleeper at the entrance; (b) sleeper under the switch blades; (c) sleeper at the closure panel; (d) sleeper under the crossing nose; (e) the longest sleeper; (f) the shortest sleeper.

Concrete is mostly classified by its compressive strength. The range of the compressive strength is defined by EN 13,230 [49] that declares "minimum compressive strength shall be class C45/55 MPa unless otherwise required by the purchaser" for the turnout sleepers as a minimum requirement. This requirement is converted into meaningful values for the modulus of elasticity via a graph in [50] that uses the formula:

$$
\mathrm{E}=2.1 \times 10^{5}(\gamma / 2.3)^{1.5}\left(\mathrm{f}_{\mathrm{c}} / 200\right)^{0.5},
$$

where $\mathrm{E}=$ modulus of elasticity $\left(\mathrm{kgf} / \mathrm{cm}^{2}\right), \gamma=$ unit weight of concrete $\left(\mathrm{t} / \mathrm{m}^{3}\right)$, and $\mathrm{f}_{\mathrm{c}}=$ specified design strength of concrete. The conversion of the minimum requirement above gives an approximate range for the modulus of elasticity of 20-50 GPa based on [50].

As can be seen from Figure 12, changing the modulus of elasticity has limited influence on the dynamic factors, ranging from 2.8 to 3.0. A similar finding could be reached for contact forces [51,52]. (Figure 12b) By contrast, the maximum bending moment distributions along a turnout are affected by different moduli of elasticity. (Figure 13) A high modulus of elasticity elevates the stiffness of a sleeper; therefore, the effective length of the sleeper supported by ballast also changes. 


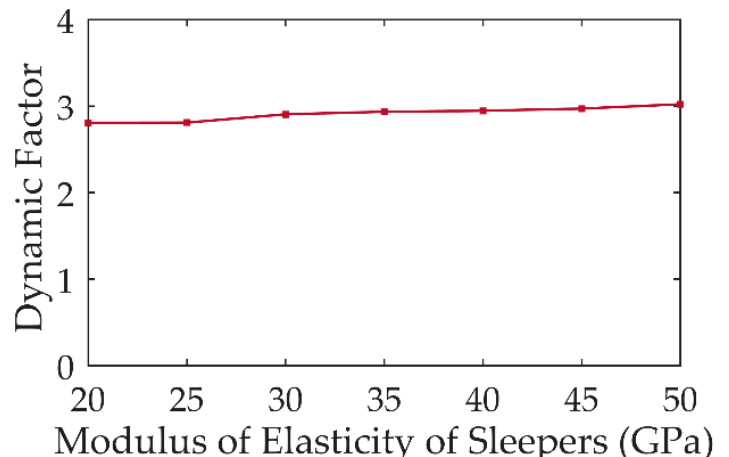

(a)

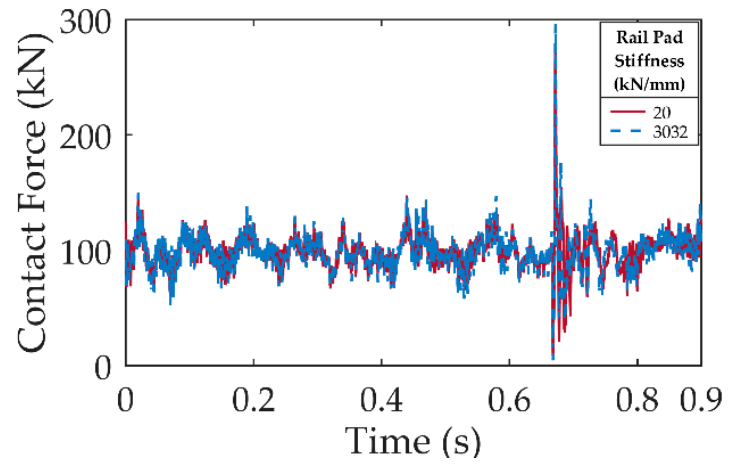

(b)

Figure 12. Effect of modulus: (a) Variations in dynamic factor which correspond to different moduli of elasticity; (b) contact forces for minimum and maximum modulus of elasticity.

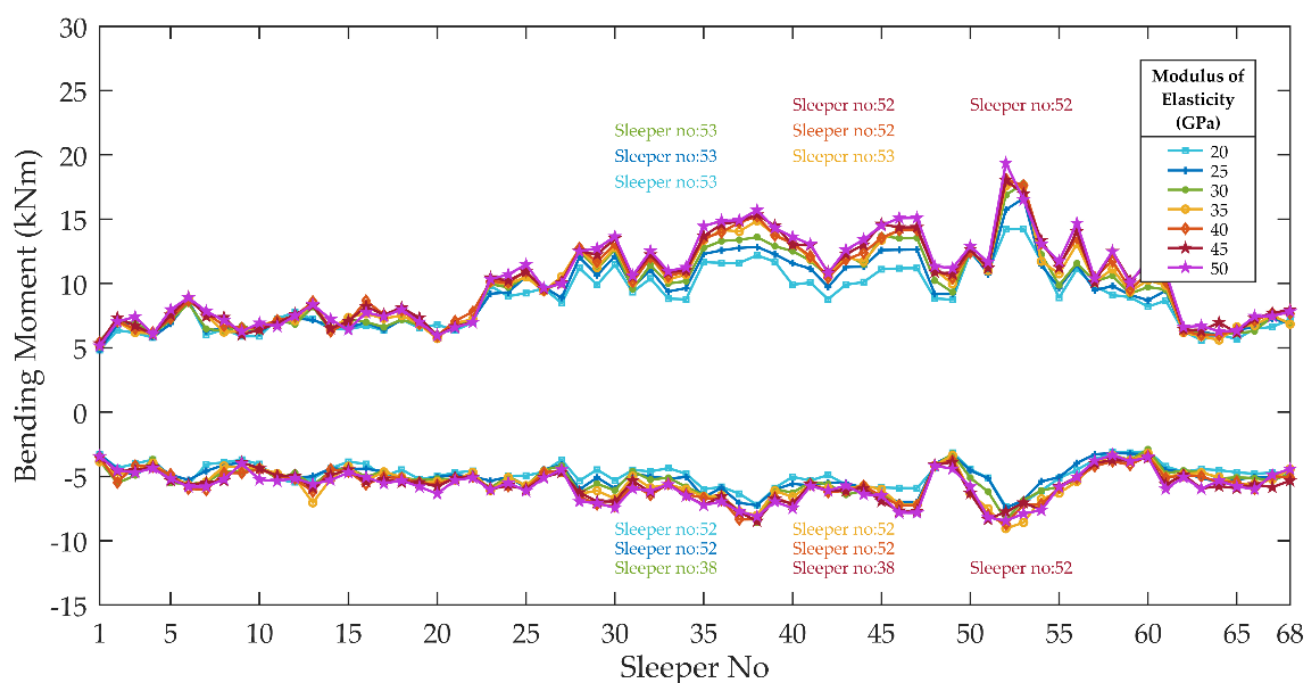

Figure 13. Longitudinal bending moment distribution with reference to various moduli of elasticity.

As a result, the bending moment of the sleeper is increased by higher moduli of elasticity according to the theory of sleeper on elastic foundation. The influence of the modulus of elasticity appears to be more effective on the sleepers at the closure panel and crossing panel. A high modulus of elasticity can contribute up to $7 \mathrm{kNm}$ in a maximum positive bending moment whereas this contribution is around $3 \mathrm{kNm}$ for maximum negative bending moments on these panels.

In Figure 14, the bending moment distributions along specific sleepers for different moduli of elasticity are presented. As can be seen from the figure, the distribution characteristics vary from one sleeper to another. For instance, most of the sleepers exhibit maximum positive bending moment at the rail seat with the highest modulus of elasticity but the sleeper under the switch blade is inconsistent with this result. Another example could be given from the graph of the sleeper under the crossing nose. It is obvious that higher moduli of elasticity increase the bending moments at the section under the crossing nose and decrease the bending moments under the opposite rail. A good pattern is distinct for most, but the highest values of the parameter exhibit unlike behavior; the maximum bending moment is higher than the expected. It is likely that the irregularities applied in the simulation contribute to these variations, changing the location impact forces. 


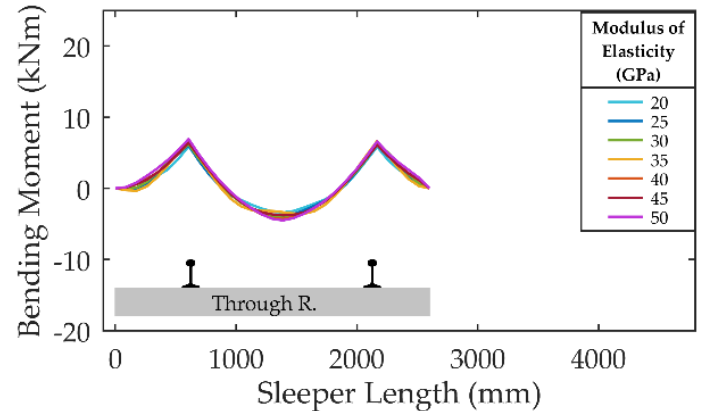

(a)

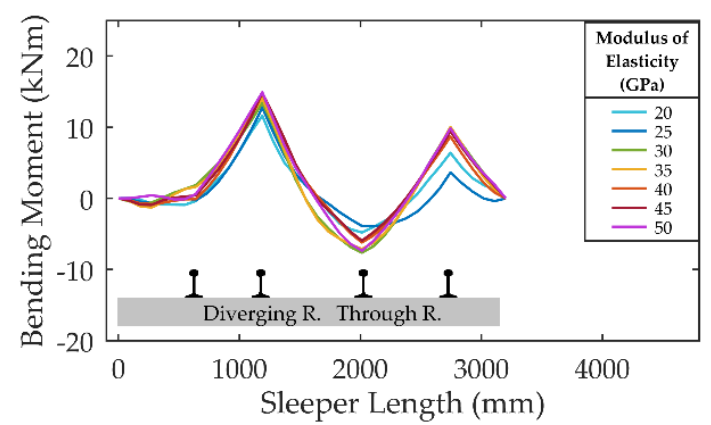

(c)

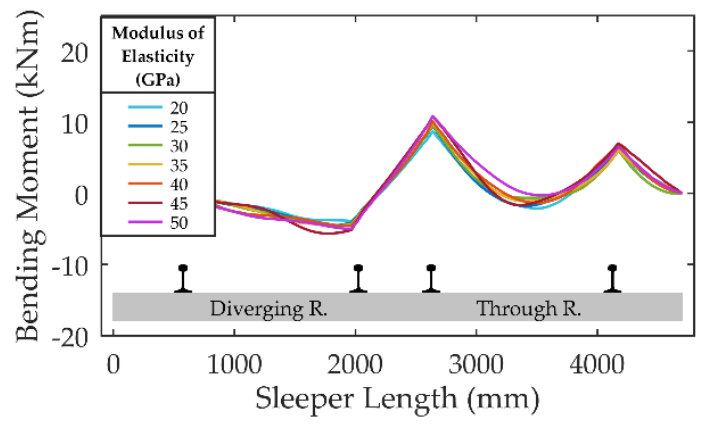

(e)

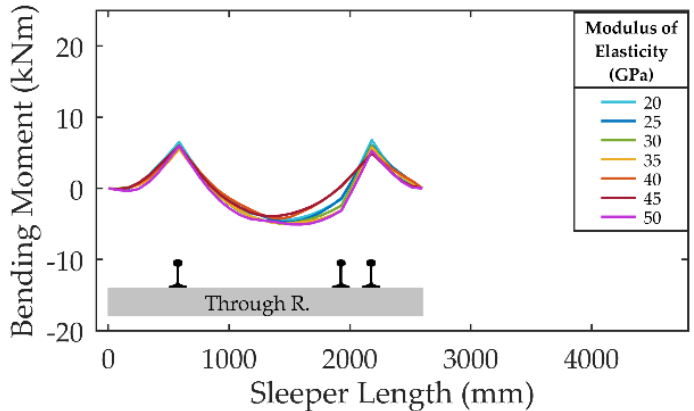

(b)

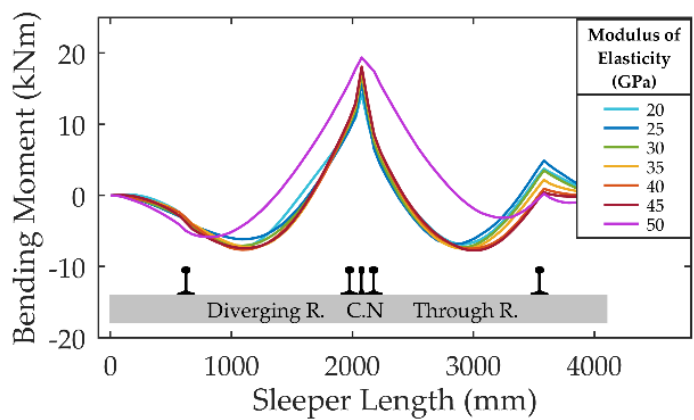

(d)

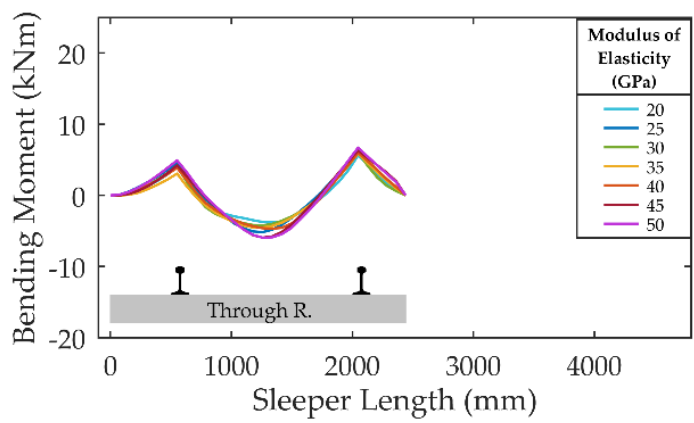

(f)

Figure 14. Bending moment distributions of specific sleepers with reference to different moduli of elasticity: (a) sleeper at the entrance; (b) sleeper under the switch blades; (c) sleeper at the closure panel; (d) sleeper under the crossing nose; (e) the longest sleeper; (f) the shortest sleeper.

Apart from concrete, the common materials in sleeper design are timber, steel, and composite materials such as Fibre-reinforced Foamed Urethane (FFU). In practice, the choice of materials can cause some drawbacks. For instance, timber sleepers are vulnerable to biological and mechanical degradation. A comparison for various materials is presented in Figure 15. The maximum positive and negative bending moments have common behavior with other simulations. For instance, the asymmetrical properties still exist on the sleepers, such as the sleeper at the closure panel. The discrepancies in bending moment distributions is more perceptible for the sleeper at closure and crossing panels. Aside from the common properties, the highest bending moment takes place when the concrete sleeper is preferred. The magnitude of the maximum positive bending moment is $17 \mathrm{kNm}$ at the section under the crossing nose. Regarding only the sleepers under the crossing nose, soft timber and FFU sleepers could be used interchangeably with those of hard timber and steel since they generally show similar bending moment distributions in general. It seems that steel could be a better choice for the sleepers under the crossing nose since they have better bending moment distributions. Nevertheless, steel sleepers are expensive, require extra care during maintenance, and are subject to corrosion. FFU could be an alternative to concrete sleepers/bearers. Specifically, it has been reported that FFU provides good mechanical properties and works well in high frequency regions [53-55]. 


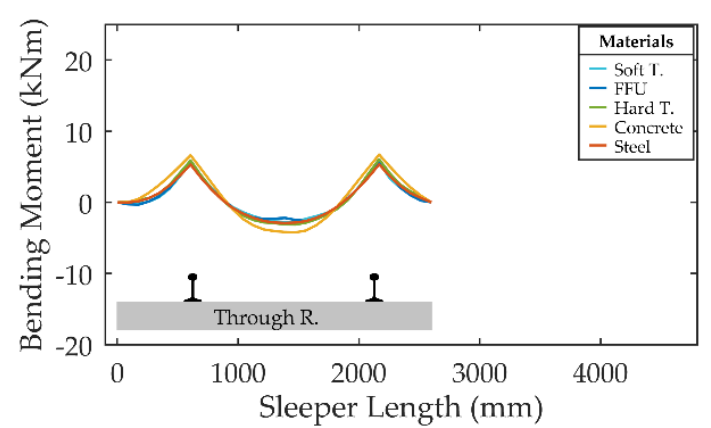

(a)

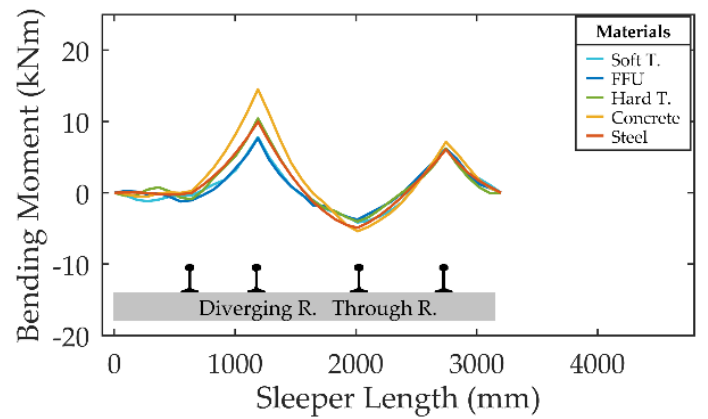

(c)

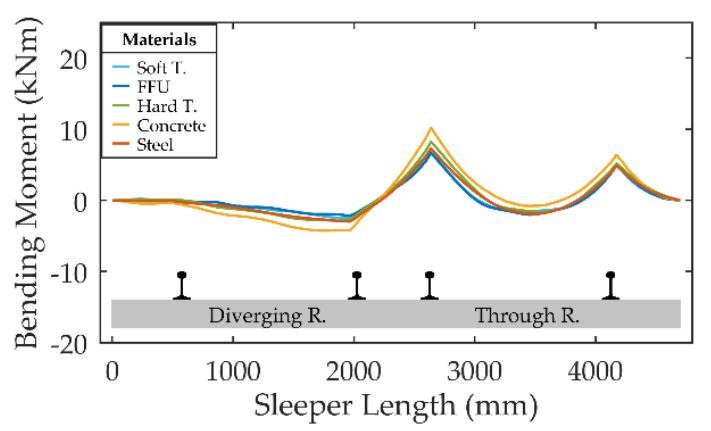

(e)

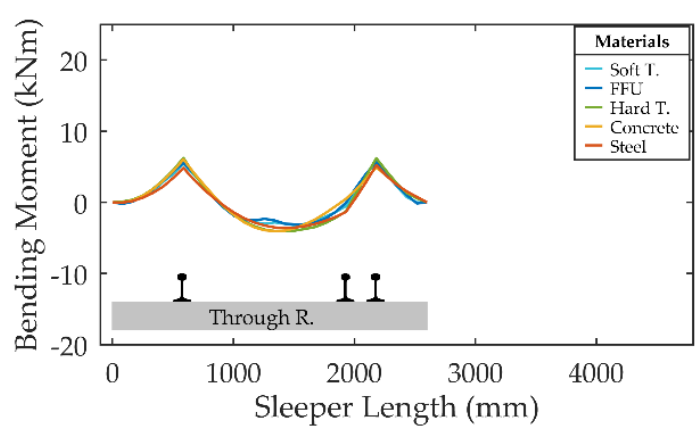

(b)

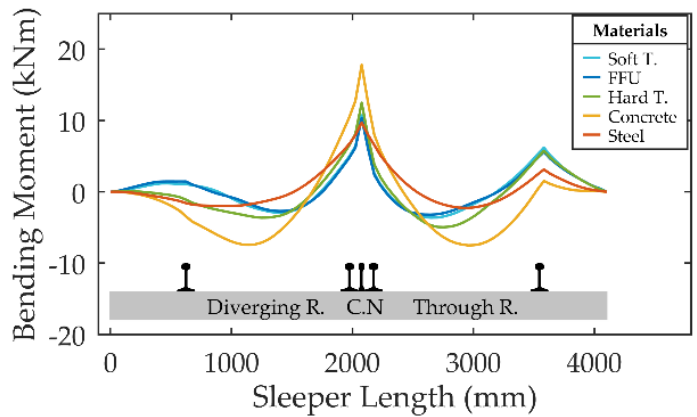

(d)

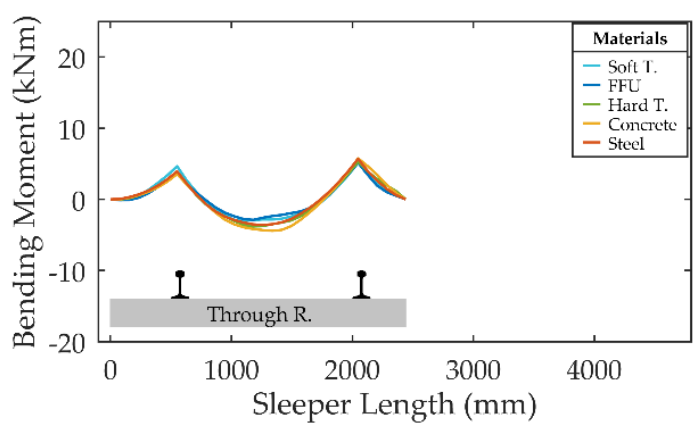

(f)

Figure 15. Bending moment distributions of specific sleepers with reference to different sleeper types: (a) sleeper at the entrance; (b) sleeper under the switch blades; (c) sleeper at the closure panel; (d) sleeper under the crossing nose; (e) the longest sleeper; (f) the shortest sleeper.

\subsubsection{Effects of Unsprung Masses}

The effective masses in the wheel-rail interaction are the unsprung (wheel) masses [6]. The effects of different unsprung masses are considered in the parametric study. The effects of the unsprung masses on both contact forces and the dynamic factor are presented in Figure 16. The dynamic factor corresponding to different wheel loads reveals an unexpected phenomenon. The reason is the definition of the dynamic factor, the maximum force (impact force) over static force. It could be inferred from the figure, that the impact forces increase with higher wheel masses and reach a horizontal asymptote. In other words, the impact forces become gradually less sensitive to higher wheel masses; in the meantime, static force always increases with wheel mass. As a consequence, the dynamic factor first shows a rise followed by a fall, which is consistent with the findings presented in [36]. Regarding Figure 16a, it can be concluded that the effect of unsprung masses on the dynamic factor is limited. By contrast, the heavier wheels have a significant effect and produce higher wheel-rail contact force fluctuations (Figure 16b) that are important for the fatigue behavior. 


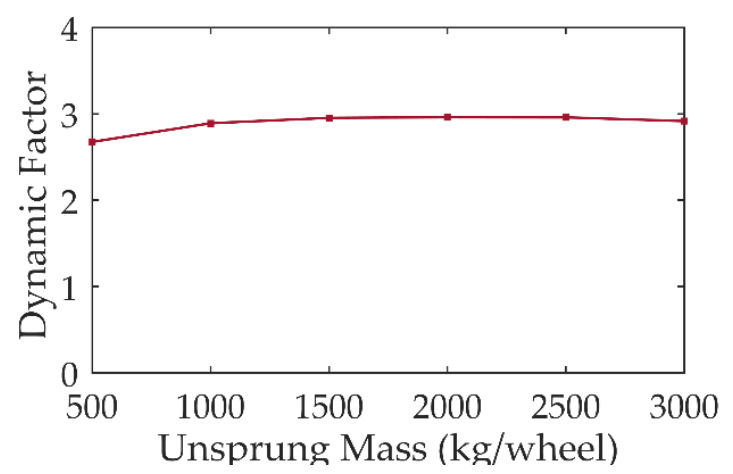

(a)

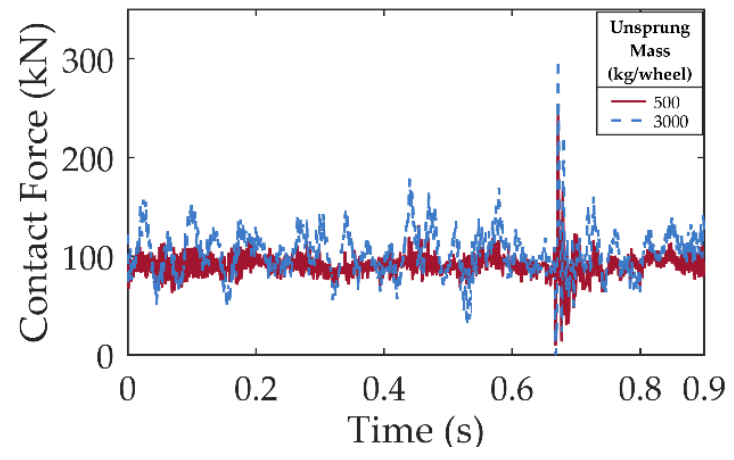

(b)

Figure 16. Effect of mass: (a) variations in dynamic factor which correspond to different wheel masses;

(b) contact forces for minimum and maximum modulus of elasticity.

In Figure 17, the longitudinal bending moment distributions of the maximum positive and negative bending moments are highlighted for different wheel masses. Heavier wheels result in higher bending moments but interestingly, seem to affect the sleepers at the closure panel rather than those under the crossing nose in terms of maximum positive bending moments. This is due to a correlation between bending moments and contact forces.

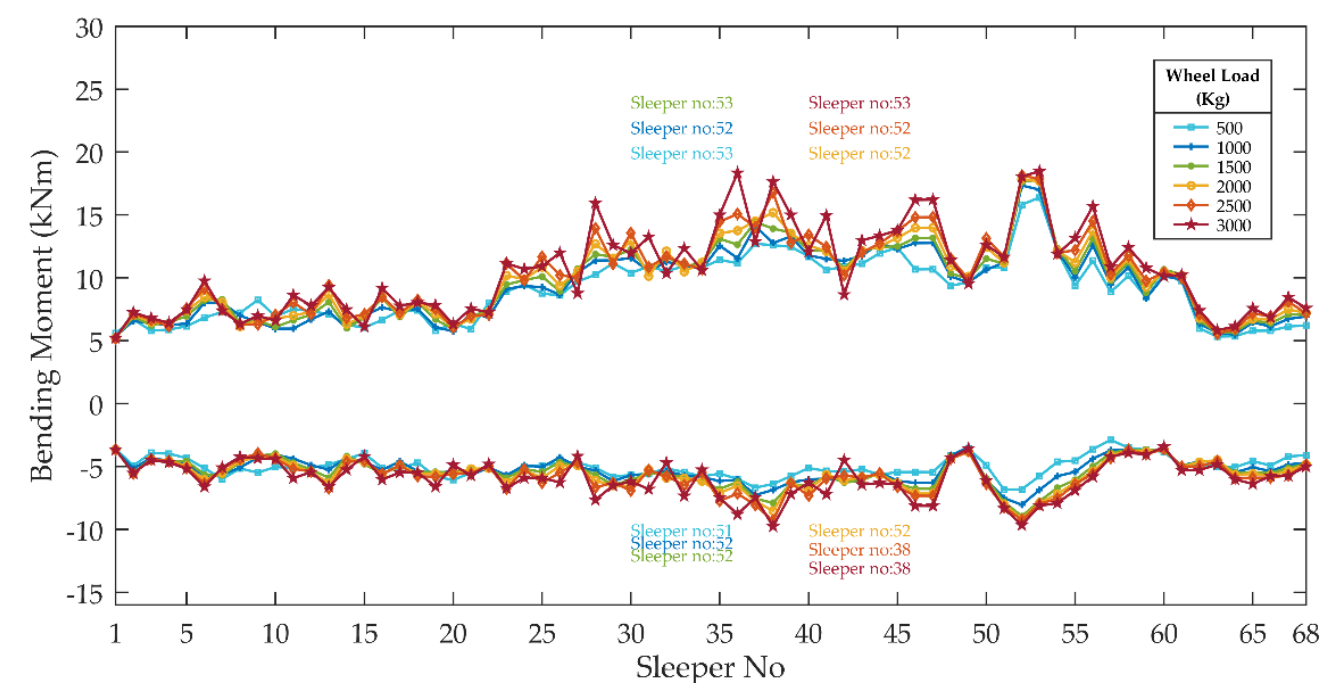

Figure 17. Longitudinal bending moment distribution with reference to different wheel loads.

As can be seen from Figure 16b, the contact force ratio of the heaviest wheel over the lightest wheel at the closure panel is higher than at the crossing panel. Accordingly, the maximum positive bending moments of the sleepers at the closure panel have higher deviations. The deviation in the maximum positive bending moment at the closure panel is around $8 \mathrm{kNm}$ whereas it is only $2.5 \mathrm{kNm}$ at the sleeper under the crossing nose. In contrast, maximum negative bending moments do not have such a character. There is no clear trend for the deviation in maximum negative bending moments. The only clear observation is that the location of the maximum negative bending moment shifts from the sleepers under the crossing nose to the sleeper at the closure panel. Finally, heavier wheel masses cause the recognizable fluctuations in the bending moment distributions for both negative and positive bending moments.

The bending moment distributions along specific sleepers under different wheel loads demonstrate no distinct behavior for most of the sleepers in Figure 18. This appears to be due to the irregularities applied in the simulation, which have been explained in the earlier section. A clear projection of the 
effect of the increased load can be seen from the figures, showing the distribution for the sleepers at the closure panel and under the crossing nose. It is obvious that higher wheel masses cause higher positive and negative bending moments along the sleepers at closure panel and under the crossing nose.

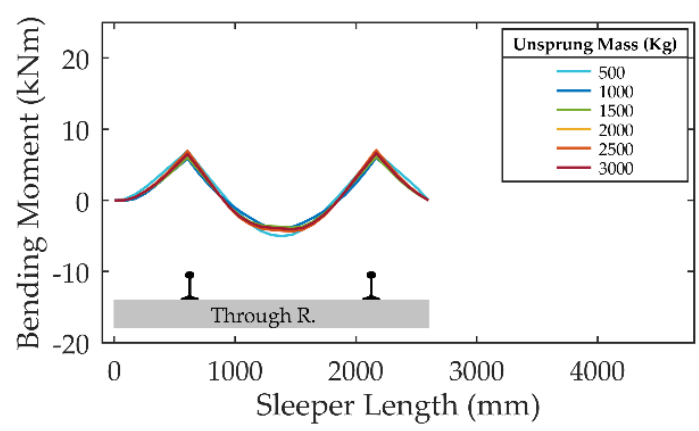

(a)

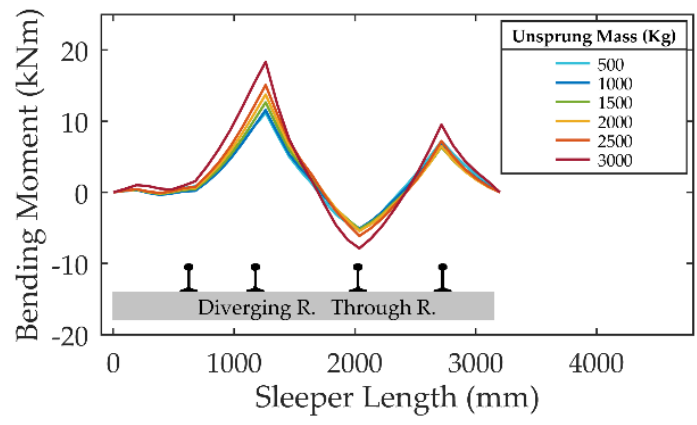

(c)

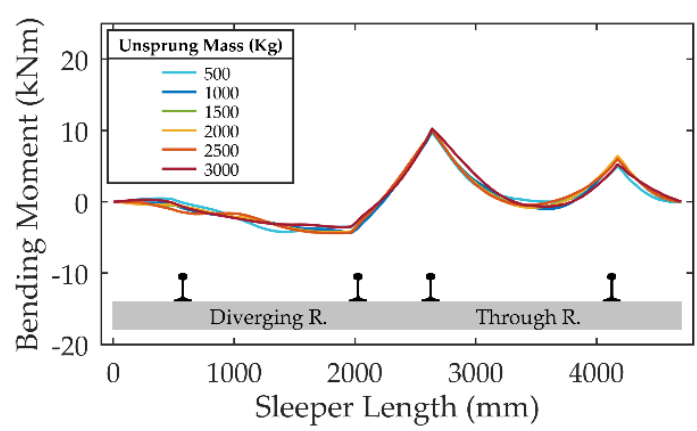

(e)

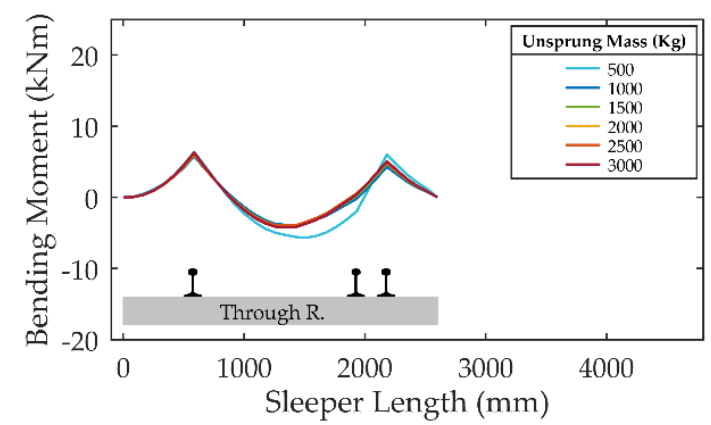

(b)

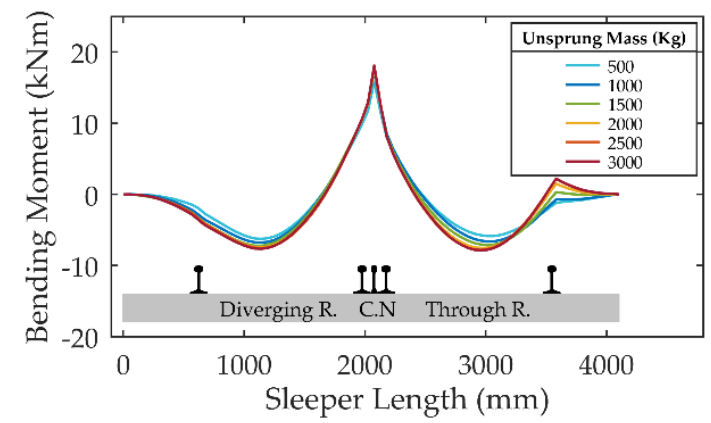

(d)

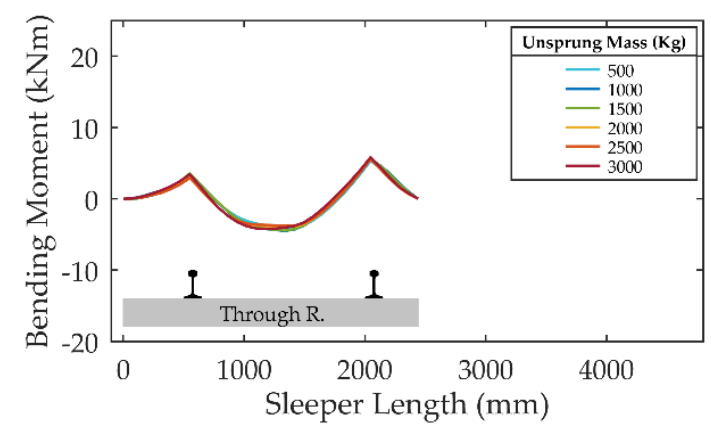

(f)

Figure 18. Bending moment distributions of specific sleepers with reference to wheel loads: (a) sleeper at the entrance; (b) sleeper under the switch blades; (c) sleeper at the closure panel; (d) sleeper under the crossing nose; (e) the longest sleeper; (f) the shortest sleeper.

\section{Conclusions}

In this study, the behaviors of turnout sleepers under dynamic loading were investigated using a three-dimensional finite element model. Additionally, the effects of variations in vehicle speed, the modulus of elasticity of sleeper materials, rail pad stiffness, and wheel load were considered. The model was verified by the results of field measurements obtained from previous studies. The results show that the sleepers under dynamic loading have a distinct behavior compared to the sleepers under static loading. Particularly, turnout bearers under the crossing nose are subjected to high asymmetrical bending moments. This dynamic effect is crucial in terms of load definitions and should be considered in design codes. Currently, there is no approved design method for railway concrete sleepers and bearers in Europe. Unlike Europe, several non-European countries use design codes for sleepers and bearers. Nevertheless, the philosophy of the design codes is based on the static loadings. Such design 
codes cannot address the effects of dynamic forces on the components (i.e., premature cracking of sleepers). As a consequence, this paper highlights the effects of dynamic loading on track components such as sleepers. It demonstrates that an approach, similar to that used in this paper, could be applied at the design stage to include the effects of dynamic forces.

This paper also highlights different conditions affecting the responses of the sleepers under dynamic loadings. The main outcome is that the maximum positive bending moment for all cases appears to occur at the sleeper section under the rail seats at the time step when the wheel load is directly applied to the rails on that sleeper. However, the matter of the location of the maximum negative bending moment cannot be directly addressed. It could be between two loaded rails or anywhere else along the sleeper. Another finding of the study is that the magnitude of the bending moment is affected mostly by variations in vehicle speeds. The most critical part, regarding only the sleepers, shifts from the sleepers at the closure panel to the sleepers under the crossing nose with reference to vehicle speed. At lower speeds, the impact forces seem to be ineffective; therefore, the concentrated rail stiffness at the crossing nose appears to impose lower bending moments on the sleepers with a magnitude of $7 \mathrm{kNm}$, which is roughly the half of maximum bending moment of the sleepers at the closure panel. Higher speeds escalate the impact forces causing higher bending moments of the sleeper under the crossing nose. This is important, showing the effect of the dynamic loadings. It is likely that static calculations neglect this effect and will point out a single point as a critical part. Furthermore, static calculations neglect the effect of irregularities which influence magnitude of dynamic response of the sleepers significantly. Results also show that specific sleepers such as the sleepers at the closure panel and under the crossing nose have asymmetrical bending moment distributions. The magnitude of the bending moment at one loaded rail seat could be two times higher than the opposite loaded rail seat, for these sleepers. This effect could be overlooked in the static calculations which would result in under or over estimation of the forces acting on the sleepers.

Parametric studies demonstrate that variations in the modulus of elasticity of the sleeper, the rail pad stiffness, and wheel load could also have a serious effect on the bending moment distributions. In general, higher values of these parameters cause higher positive and negative bending moments. In particular, the rail pad stiffness is effective to a certain level then the effects on the bending moments become insignificant. Conversely, higher wheel loads always increase the impact forces, but the normal track forces could be more responsive. Therefore, the critical part of the track could shift to different locations with response to track irregularities. Similarly, the higher modulus of elasticity causes higher bending moments; however, it is more noticeable for the longer sleepers and severe track irregularities. Parametric studies show that among the various sleeper types, the concrete produces the highest bending positive moment at the sleeper section under the crossing nose. Due to its high bending stiffness, the difference in the bending moments of the sleeper sections between the oppositely loaded rails show a great difference. By contrast, FFU seems to distribute bending moments more effectively. FFU could be effective in lowering bending moments at the sleeper under the crossing nose. As aforementioned, FFU is reported effective in the high frequency region and therefore, it seems suitable for the sleepers under the crossing nose where high frequency forces occur.

Last but not least, the methodology applied in this study is considered to be applicable for modelling and analyzing an entire turnout due to the lack of computational power in current technology. However, it is limited and cannot reflect the nature of the system's behavior at the stress-strain level. Nevertheless, this methodology can help researchers decide on sections of interest for more detailed analyses.

Author Contributions: Conceptualization, M.H. and S.K.; methodology, M.H. and S.K.; software, M.H. and M.S.; validation, M.H., S.K. and M.P.; formal analysis, M.H.; investigation, M.H. and S.K.; resources, S.K. and M.S.; data curation, M.H. and M.S.; writing—original draft preparation, M.H.; writing—review and editing, S.K. and M.P.; visualization, M.H.; supervision, S.K. and M.S.; project administration, S.K.; funding acquisition, S.K.

Funding: This research was funded by European Commission, grant numbers: H2020-MSCA-RISE No. 691135 and H2020-S2R No. 730849. The APC was funded by MDPI's Invited Paper Program. 
Acknowledgments: The corresponding author wishes to gratefully acknowledge the Japan Society for Promotion of Science (JSPS) for his JSPS Invitation Research Fellowship (Long-term), Grant No. L15701, at the Track Dynamics Laboratory, Railway Technical Research Institute and at Concrete Laboratory, the University of Tokyo, Tokyo, Japan. The JSPS financially supports this work as part of the research project, entitled "Smart and reliable railway infrastructure". Special thanks to European Commission for H2020-MSCA-RISE Project No. 691135 "RISEN: Rail Infrastructure Systems Engineering Net-work" (www.risen2rail.eu) [56,57]. Partial support from H2020 Shift2Rail Project No. 730849 (S-Code) is acknowledged. In addition, the sponsorships and assistance from LORAM, Network Rail, RSSB (Rail Safety and Standard Board, UK) are highly appreciated.

Conflicts of Interest: The authors declare no conflict of interest.

\section{References}

1. Nissen, A. LCC analysis for switches and crossings: A case study from the Swedish Railway Network. Int. J. Comadem 2009, 12, 10-19.

2. Cornish, A. Life-Time Monitoring of in Service Switches and Crossings through Field Experimentation. Ph.D. Thesis, Imperial College London, London, UK, 2014.

3. Dindar, S.; Kaewunruen, S.; An, M. Identification of appropriate risk analysis techniques for railway turnout systems. J. Risk Res. 2016, 21, 974-995. [CrossRef]

4. EIM-EFRTC-CER. Market Strategy Report-Track Maintenance \& Renewal; The Community of European Railway and Infrastructure Companies (CER): Brussels, Belgium, 2012.

5. Pålsson, B.A. Optimisation of railway crossing geometry considering a representative set of wheel profiles. Veh. Syst. Dyn. 2015, 53, 274-301. [CrossRef]

6. Esveld, C. Modern Railway Track, 2nd ed.; Delft University of Technology: Zaltbommel, The Netherlands, 2001.

7. Kaewunruen, S. Monitoring structural deterioration of railway turnout systems via dynamic wheel/rail interaction. Case Stud. Nondestruct. Test. Eval. 2014, 1, 19-24. [CrossRef]

8. Markine, V.; Steenbergen, M.; Shevtsov, I. Combatting RCF on switch points by tuning elastic track properties. Wear 2011, 271, 158-167. [CrossRef]

9. Sae Siew, J.; Mirza, O.; Kaewunruen, S. Torsional effect on track-support structures of railway turnouts crossing impact. J. Transp. Eng. Part A Syst. 2016, 143, 06016001. [CrossRef]

10. Wan, C.; Markine, V.L.; Shevtsov, I.Y. Analysis of train/turnout vertical interaction using a fast numerical model and validation of that model. Proc. Inst. Mech. Eng. Part F J. Rail Rapid Transit 2014, 228, 730-743. [CrossRef]

11. Andersson, C.; Dahlberg, T. Wheel/rail impacts at a railway turnout crossing. Proc. Inst. Mech. Eng. Part F J. Rail Rapid Transit 1998, 212, 123-134. [CrossRef]

12. Kassa, E.; Andersson, C.; Nielsen, J.C.O. Simulation of dynamic interaction between train and railway turnout. Veh. Syst. Dyn. 2006, 44, 247-258. [CrossRef]

13. Dindar, S.; Kaewunruen, S.; An, M.; Sussman, J.M. Bayesian Network-based probability analysis of train derailments caused by various extreme weather patterns on railway turnouts. Saf. Sci. 2018, 110, 20-30. [CrossRef]

14. Xin, L.; Markine, V.; Shevtsov, I. Analysis of the effect of repair welding/grinding on the performance of railway crossings using field measurements and finite element modeling. Proc. Inst. Mech. Eng. Part F J. Rail Rapid Transit 2018, 232, 798-815. [CrossRef]

15. Wang, G.; Xu, T.; Tang, T.; Yuan, T.; Wang, H. A Bayesian network model for prediction of weather-related failures in railway turnout systems. Expert Syst. Appl. 2017, 69, 247-256. [CrossRef]

16. Dindar, S.; Kaewunruen, S.; An, M. Rail accident analysis using large-scale investigations of train derailments on switches and crossings: Comparing the performances of a novel stochastic mathematical prediction and various assumptions. Eng. Fail. Anal. 2019, 103, 203-216. [CrossRef]

17. Kaewunruen, S.; Osman, M.H.; Eric, W.H.C. Risk-Based Maintenance Planning for Rail Fastening Systems. ASCE-ASME J. Risk Uncertain. Eng. Syst. Part A Civ. Eng. 2019, 5, 04019007. [CrossRef]

18. Kaewunruen, S.; Lian, Q. Digital twin aided sustainability-based lifecycle management for railway turnout systems. J. Clean. Prod. 2019, 228, 1537-1551. [CrossRef]

19. Kaewunruen, S.; Rungskunroch, P.; Jennings, D.V. A through-life evaluation of end-of-life rolling stocks considering asset recycling, energy recovering, and financial benefit. J. Clean. Prod. 2019, 212, 1008-1024. [CrossRef] 
20. You, R.; Kaewunruen, S. Evaluation of remaining fatigue life of concrete sleeper based on field loading conditions. Eng. Fail. Anal. 2019, 105, 70-86. [CrossRef]

21. Wan, C.; Markine, V.; Shevtsov, I. Improvement of vehicle-turnout interaction by optimising the shape of crossing nose. Veh. Syst. Dyn. 2014, 52, 1517-1540. [CrossRef]

22. Grossoni, I.; Bezin, Y.; Neves, S. Optimisation of support stiffness at railway crossings. Veh. Syst. Dyn. 2018, 56, 1072-1096. [CrossRef]

23. Burgelman, N.; Sichani, M.S.; Enblom, R.; Berg, M.; Li, Z.; Dollevoet, R. Influence of wheel-rail contact modelling on vehicle dynamic simulation. Veh. Syst. Dyn. 2015, 53, 1190-1203. [CrossRef]

24. Hamarat, M.Z.; Kaewunruen, S.; Papaelias, M. Contact Conditions over Turnout Crossing Noses. IOP Conf. Ser. Mater. Sci. Eng. 2019, 471, 062027. [CrossRef]

25. Kassa, E.; Nielsen, J.C. Dynamic train-turnout interaction in an extended frequency range using a detailed model of track dynamics. J. Sound Vib. 2009, 320, 893-914. [CrossRef]

26. Kaewunruen, S.; Remennikov, A.M. Progressive failure of prestressed concrete sleepers under multiple high-intensity impact loads. Eng. Struct. 2009, 31, 2460-2473. [CrossRef]

27. Ma, Y.; Mashal, A.A.; Markine, V.L. Modelling and experimental validation of dynamic impact in 1:9 railway crossing panel. Tribol. Int. 2018, 118, 208-226. [CrossRef]

28. Pletz, M.; Daves, W.; Ossberger, H. A wheel set/crossing model regarding impact, sliding and deformation-Explicit finite element approach. Wear 2012, 294, 446-456. [CrossRef]

29. Wei, Z.; Li, Z.; Qian, Z.; Chen, R.; Dollevoet, R. 3D FE modelling and validation of frictional contact with partial slip in compression-shift-rolling evolution. Int. J. Rail Transp. 2016, 4, 20-36. [CrossRef]

30. Skrypnyk, R.; Nielsen, J.C.; Ekh, M.; Pålsson, B.A. Metamodelling of wheel-rail normal contact in railway crossings with elasto-plastic material behaviour. Eng. Comput. 2019, 35, 139-155. [CrossRef]

31. Manalo, A.; Aravinthan, T.; Karunasena, W.; Stevens, N. Analysis of a typical railway turnout sleeper system using grillage beam analogy. Finite Elem. Anal. Des. 2012, 48, 1376-1391. [CrossRef]

32. Sae Siew, J.; Mirza, O.; Kaewunruen, S. Nonlinear finite element modelling of railway turnout system considering bearer/sleeper-ballast interaction. J. Struct. 2015, 2015, 598562. [CrossRef]

33. Kaewunruen, S.; Li, D.; Remennikov, A.; Ishida, T. Dynamic Resistance and Rational Design of Railway Prestressed Concrete Sleepers. In Proceedings of the fib Symposium 2019, Krakow, Poland, 27-29 May 2019.

34. Wan, C.; Markine, V.; Shevtsov, I. Optimisation of the elastic track properties of turnout crossings. Proc. Inst. Mech. Eng. Part F J. Rail Rapid Transit 2016, 230, 360-373. [CrossRef]

35. Thompson, D.; Van Vliet, W.; Verheij, J. Developments of the indirect method for measuring the high frequency dynamic stiffness of resilient elements. J. Sound Vib. 1998, 213, 169-188. [CrossRef]

36. Jenkins, H.; Stephenson, J.; Clayton, G.; Morland, G.; Lyon, D. The effect of track and vehicle parameters on wheel/rail vertical dynamic forces. Railw. Eng. J. 1974, 3, 2-16.

37. Hamarat, M.; Papaelias, M.; Kaewunruen, S.; Silvast, M. Dynamic analysis of a railway turnout system under moving train loads. In Proceedings of the Acoustics 2019, Milton Keynes, UK, 13-15 May 2019.

38. Hallquist, J.O. LS-DYNA keyword user's manual. Livermore Softw. Technol. Corp. 2007, 970, $299-800$.

39. Pålsson, B.A.; Nielsen, J.C. Dynamic vehicle-track interaction in switches and crossings and the influence of rail pad stiffness-field measurements and validation of a simulation model. Veh. Syst. Dyn. 2015, 53, 734-755. [CrossRef]

40. Wei, Z.; Núñez, A.; Li, Z.; Dollevoet, R. Evaluating degradation at railway crossings using axle box acceleration measurements. Sensors 2017, 17, 2236.

41. Kassa, E.; Nielsen, J.C. Dynamic interaction between train and railway turnout: Full-scale field test and validation of simulation models. Veh. Syst. Dyn. 2008, 46, 521-534. [CrossRef]

42. RRSB. Signing of Permissble Speeds and Speed Restrictions; Safety \& Standards Directorate Railtrack PLC: London, UK, 2000.

43. RRSB. Permissible Track Forces for Railway Vehicles; Group Standards Railway Technical Centre: Derby, UK, 1993.

44. Grossoni, I.; Iwnicki, S.; Bezin, Y.; Gong, C. Dynamics of a vehicle-track coupling system at a rail joint. Proc. Inst. Mech. Eng. Part F J. Rail Rapid Transit 2015, 229, 364-374. [CrossRef]

45. Gullers, P.; Andersson, L.; Lundén, R. High-frequency vertical wheel-rail contact forces-Field measurements and influence of track irregularities. Wear 2008, 265, 1472-1478. [CrossRef]

46. Schijve, J. Fatigue of Structures and Materials; Springer Science \& Business Media: New Delhi, India, 2001. 
47. Powrie, W.; Le Pen, L. A Guide to Track Stiffness; University of Southampton Press: Southampton, UK, 2016.

48. Kaewunruen, S.; Remennikov, A. Dynamic Properties of Railway Track and Its Components: A State-Of-The-Art Review; Weiss, B.N., Ed.; New Research on Acoustics, Nova Science Publishers: New York, NY, USA, 2008.

49. European Committee for Standardization. EN 13230: Parts 1. Railway Applications-Track-Concrete Sleepers and Bearers; European Committee for Standardization: Brussels, Belgium, 2016.

50. Tomosawa, F.; Noguchi, T. Relationship between compressive strength and modulus of elasticity of high-strength concrete. In Proceedings of the Third International Symposium on Utilization of High-Strength Concrete, Montpellier, France, 2-4 October 2017; pp. 1247-1254.

51. Kaewunruen, S.; Ngamkhanong, C.; Ng, J. Influence of time-dependent material degradation on life cycle serviceability of interspersed railway tracks due to moving train loads. Eng. Struct. 2019, 199, 109625. [CrossRef]

52. Janeliukstis, R.; Kaewunruen, S. A Novel Separation Technique of Flexural Loading-Induced Acoustic Emission Sources in Railway Prestressed Concrete Sleepers. IEEE Access 2019, 7, 51426-51440. [CrossRef]

53. Kaewunruen, S. Monitoring in-service performance of fibre-reinforced foamed urethane sleepers/bearers in railway urban turnout systems. Struct. Monit. Maint. 2014, 1, 131-157. [CrossRef]

54. Kaewunruen, S. Acoustic and dynamic characteristics of a complex urban turnout using fibre-reinforced foamed urethane (FFU) bearers. In Noise and Vibration Mitigation for Rail Transportation Systems; Springer: Berlin, Germany, 2015; pp. 377-384. [CrossRef]

55. Kaewunruen, S.; You, R.; Ishida, M. Composites for timber-replacement bearers in railway switches and crossings. Infrastructures 2017, 2, 13. [CrossRef]

56. Kaewunruen, S.; Remennikov, A.M.; Murray, M.H. Introducing a new limit states design concept to railway concrete sleepers: An Australian experience. Front. Mat. 2014, 1, 8. [CrossRef]

57. Kaewunruen, S.; Sussman, J.M.; Matsumoto, A. Grand challenges in transportation and transit systems. Front. Built Environ. 2016, 2, 4. [CrossRef]

(C) 2019 by the authors. Licensee MDPI, Basel, Switzerland. This article is an open access article distributed under the terms and conditions of the Creative Commons Attribution (CC BY) license (http://creativecommons.org/licenses/by/4.0/). 